\title{
The Quantum Unconscious and the Observant Consciousness*
}

\author{
Rui Freire Lucas \\ Neuchâtel Psychiatric Centre, Neuchâtel, Switzerland \\ Email: ruifreirelucas@gmail.com
}

Received 4 May 2016; accepted 13 June 2016; published 16 June 2016

Copyright (C) 2016 by author and Scientific Research Publishing Inc.

This work is licensed under the Creative Commons Attribution International License (CC BY). http://creativecommons.org/licenses/by/4.0/

c) (i) Open Access

\begin{abstract}
Based on the philosophy of Henri Bergson and the contemporary developments of Quantum Physics, I sought to demonstrate how these developments are incompatible with a positivist vision of reality, which is still influential in the scientific community. Specifically, in the field of Psychoanalysis, I have shown how this outdated epistemology has been responsible for a manic denial of the theories of Carl Gustav Jung and Wilfred Bion (later stage) as part of an immobilising allegiance to a schizo-paranoid functional tradition imposed by its founder. Finally, I have proposed that supported by the formulations of these renegade analysts, psychoanalysis can progress to a depressive position, eventually transmitting this integrated perspective of reality to the rest of the scientific community and postmodern society in general.
\end{abstract}

\section{Keywords}

Unconscious, Observation, Quantum Mechanics, Psychoanalysis, Epistemological Reformulation

\section{Introduction}

"Omniscience [on the principle of tout savoir tout condamner] substitutes for the discrimination between true and false a dictatorial affirmation that one thing is morally right and the other wrong. The assumption of omniscience that denies reality ensures that the morality thus engendered is a function of psychosis.”

\section{W. Bion}

The Promethean ${ }^{1}$ myth tells the story of a titan who, in open defiance of Zeus, decides to violate his rules and transmit divine knowledge to humanity. For this reason, Prometheus is condemned by Zeus to eternal exile in

\footnotetext{
"Thesis defended in 2013 at the end of the author's training program in Intensive Psychoanalytic Psychotherapy at the Tavistock and Portman NHS Foundation Trust.

${ }^{1}$ From the Greek Про $\mu \eta \theta \varepsilon \dot{\varsigma} \varsigma=$ forethinker.
} 
Tartarus, chained to a rock, with his liver—which had been regenerated during the previous night—being devoured every day by a vulture. This myth, which has been repeatedly mentioned throughout history (Athanassakis, 2004) since its first reference by Hesiod in the eighth century B.C., currently represents a symbol of the conquest of knowledge by man (in particular scientific knowledge), despite the resistance and threat imposed by the prevailing orthodoxies ${ }^{2}$. We have seen this phenomenon manifest itself over several centuries in the history of Science, in which countless scientists saw their advances blocked by the established powers who, in an unreasonable manner, refused to look further through the Galilean telescope, fearing that whatever they would have seen could have called their authority into question ${ }^{3}$. Conceived by Sigmund Freud as a science, psychoanalysis was no exception to this rule.

We now know, thanks to the formulations of psychoanalysis, that the conflict between Prometheus and Zeus represents a continuation of a series of parent-child conflicts dating back to the cosmic conflicts between Zeus and Cronus and, before this, between Cronus and Uranus, which, according to mythology, determined the destiny of mankind (Caldwell, 1993). Recognizing the universality and importance of these conflicts, Sigmund Freud puts them at the centre of his theory, defining them as one of its shibboleths ${ }^{4}$. Surprisingly, however, he fails to recognize, throughout his life and work, the origin of his ideas-his own father-complex ${ }^{5}$.

For the father of psychoanalysis, this complex was the one responsible for a blind intransigence in the affirmation of psychoanalysis in accordance with the conventional positivist scientific standards from Vienna at the fin-du-siècle, and also for the careful search for a trustworthy successor-preferably Aryan, to definitively mark his movement from his Jewish identity-who would have continued his project in an uncritical submission to the orthodoxy he had established.

All seemed to be going well for Freud until the moment when C. G. Jung-his "crown prince" (McGuire, 1974: p. 218)—began to oppose him, eventually denouncing the shortcomings of his theory. This betrayal inevitably triggered in Freud a strong castration anxiety that manifested itself in the form of a Secret Committee created for his defence and to preserve the purity of his doctrines (Grosskurth, 1991, 1998) ${ }^{6}$. Affected by the Oedipal hostility of its father, this Committee would, therefore, be responsible for mobilizing a defaming and demeaning campaign against Jung — characterized by Roustang as an "assassination plot" designed to eliminate “a traitor" (Roustang, 1986: p. 4)—eventually sentencing him to eternal exile from psychoanalysis ${ }^{7}$.

Surprisingly, this complex resisted psychoanalytic (self-) analysis and was passed along to future generations, together with the urge to repeat its symptoms. As Jung did, Wilfred Bion, with his proposal for an epistemo-

\footnotetext{
${ }^{2}$ This myth has as an equivalent, in Christianity, the myth of Eden, in which Adam and Eve are cast out of Paradise by God after consuming the forbidden fruit, taken from the tree of knowledge of good and evil.

${ }^{3}$ Koestler describes this phenomenon as follows: "The new territory opened up by the impetuous advance of a few geniuses, acting as a spearhead, is subsequently occupied by the solid phalanxes of mediocrity; and soon the revolution turns into a new orthodoxy, with its unavoidable symptoms of one-sidedness, over specialization, loss of contact with other provinces of knowledge, and, ultimately, estrangement from reality. We see this happening - unavoidable, it seems - at various times in the history of various sciences. The emergent orthodoxy hardens into a 'closed system' of thought, unwilling or unable to assimilate new empirical data or to adjust itself to significant changes in other fields of knowledge” (Koestler, 1975: p. 225).

${ }^{4}$ “'The assumption that there are unconscious mental processes, the recognition of the theory of resistance and repression, the appreciation of the importance of sexuality and of the Oedipus complex - these constitute the principle subject-matter of Psycho-analysis and the foundations of its theory. No one who cannot accept them all should count himself a psycho-analyst” (Freud, 1923: p. 247).

${ }^{5}$ This fact was noted for the first time in 1929 by Maylan (1929) through analysis of the autobiographical material provided by Freud throughout his work. Various studies have subsequently been published supporting the existence of a father-complex in Freud (see for example: Yerushalmi, 1993). Additionally, Ernest Jones, in his 1913 article on the God-complex, reveals an "attitude of disinclination towards the acceptance of new knowledge” (Jones, 1909-1910: p. 256) on the part of Freud, in a divine identification of Zeus (Roazen, 1973: p. 353).

Because this complex remained repressed, much will have contributed to Freud's refusal to submit to a personal (hetero-)analysis by any of his followers, for fear of losing his authority in this process (Billinsky, 1969: p. 43).

${ }^{6}$ Upon the suggestion of Ernest Jones, a Secret Committee was founded on May 25, 1913, in Freud's office to protect Freud and expel Jung from the psychoanalytic movement. This committee, which was composed during Jung's presidency of the International Psychoanalytic Association, included, in addition to Freud, Ernest Jones, Sandor Ferenczi, Max Eitingon, Hanns Sachs, Otto Rank, and Karl Abraham. The committee even held a ceremony involving the presentation of antique Greek intaglios mounted in gold rings by Freud to the other members, in which he used an intaglio with the representation of the head of Zeus.

In this group, the "brothers" competed for the empty seat left by Jung; however, in the end, none of them became the successor, and it was Freud's “frail child”, Anna Freud, who ended up being his rightful heir, as Athena was generated from the cleaved head of Zeus (Webster, 1995).

${ }^{7}$ We can see the post-mortem oppression and authority of Freud in a report from another renegade psychoanalyst—Donald Winnicott—who, after coming to Jung's defence by stating "If we fail to come to terms with Jung we are self-proclaimed partisans, partisans in a false cause" (Winnicott, 1964: p. 450), describes the following dream: “1) There was absolute destruction, and I was part of the world and of all people, and therefore I was being destroyed... 2) Then there was absolute destruction, and I was the destructive agent... 3) ....in the dream I awakened. As I awakened I knew that I had dreamed both (1) and (2)” (Winnicott, 1963: p. 228-230).
} 
logical reformulation of psychoanalysis in the later stage of his career, also witnessed the revival of this Praetorian Guard, now represented by orthodox Kleinians, that was once again committed to the discrediting and annihilating the detractor and his work ${ }^{8}$.

What makes these experts, in the identification and interpretation of unconscious mental phenomena, show themselves to some extent immune to their knowledge? Even today, when personal analysis is required for analytical training, structural anxieties resistant to therapeutic insight seem to persist in most of this community.

With these issues in mind, I will seek to show in this work how, as Prometheus was, Jung and Bion were forward thinkers who had the audacity to challenge the psychoanalytic establishment by overcoming their resistances for the benefit of an approximation to the truth despite envisioning ostracism by their peers and daily attacks by Zeus' vulture. I will also seek to show how, in the depths of Tartarus, these analysts faced primitive anxieties, integrating a modern divided view of reality while facing the smallness and helplessness of their existence in a universe that is always seeking to annihilate us.

I will do this with the support of contemporary philosophical and scientific developments, in particular from the formulations of Henri Bergson and of Quantum Physics. Taking advantage of a convergent interdisciplinary evolution of the study of reality, I will seek to denounce, in a non-technical but reliable manner, precisely the point where these disciplines intersect, thus establishing, where appropriate, a synonymy between their terms and their main assumptions.

I will start with a brief foray through the various developmental stages of science in the Western world, denouncing how, since its emergence by vesiculation from philosophy, science has attained a complete self-reliance on the positivism of the twentieth century.

\section{Science: From the Part to the Whole}

"The positing of the ultimacy of rationality unmasks itself as a belief which cannot be rationally justified... Indeed, in our times belief in reason is increasingly characterized as a commitment to reason which itself lacks rational grounds.”

\section{H. Hart}

Since its birth in ancient Greece, the concept of science has undergone various transformations in the Western world. Originating from a comprehensive "love of knowledge", science did not show itself $a b$ initio as knowledge distinct from Philosophy. Only with Aristotle, from the sixth century B.C. onwards, were the positive sciences clearly defined as autonomous disciplines, remaining nevertheless under the aegis of Philosophy, still considered the science of primary principles. Despite the prioritary importance attributed to Philosophy, this categorization favoured the individual development of these disciplines, which essentially remained until the Renaissance, when new scientific discoveries permanently broke the Aristotelian image of the world (Barnes, 1995).

Thus, if until this point, Science/Philosophy had exhibited an essentially contemplative nature-searching for understanding and interpretation of the world, without any type of operation on nature-from the thirteenth century onwards, science was conceived as knowledge that, in addition to theoretical objectives, should also display, through intervention and experimentation with nature, immediate practical objectives.

Nevertheless, the connection between science and Philosophy remained very close in the subsequent centuries, with eminent thinkers such as Descartes, Newton, and Leibniz considering themselves both philosophers and scientists ${ }^{9}$. Only in the nineteenth century, faced with the inability to reconcile progressive scientific specialization with emerging irrationalistic thought, was a fundamental divide established between these two ways of obtaining knowledge.

In particular, in reaction to the essentially speculative and metaphysical character of German idealism at that

\footnotetext{
${ }^{8}$ Bion was also ostracized by the orthodox psychoanalysts after introducing the metaphysical concept of the "O". A senior Kleinian would say that his works were only of quality until Elements of Psycho-analysis (1963), while others proclaimed that his later work was nothing but the writings of a senile man (Symington \& Symington, 2002). Today, we can still observe this controversy in articles such as Vermote (2011) (introduced by Blass), recently published in the International Journal of Psychoanalysis.

${ }^{9}$ In fact, although traditionally associated with a materialistic and deterministic conception of reality, both Descartes (Dicker, 2013) and Newton (Dobbs, 1991) conceptualized, on the basis of their formulations, the existence of an absolute reality, or God, ultimately responsible for the existence of the phenomenal world. Nevertheless, committed to insulating scientific research from theological dogma, their followers chose to neglect the study of the Cartesian Meditations and Newton's Theology, instead placing an emphasis on the naturalistic aspects of their works - that is, Method and Mechanics.
} 
point in time, interest in more pragmatic issues arose; this was generally linked to the problem of the foundation of the positive social sciences, which were inspired by traditional empiricism. A critically important movement in relation to this aspect was positivism, founded by Auguste Comte (1798-1857), which, in the theory of the three stages of development of human history, proposed that in the last stage- the positive-philosophical thought should be limited to the description of sensible phenomena and the general laws of the sciences (Comte \& Lenzer, 1998).

This positivist spirit, which strongly marks the transition to the twentieth century, renounces, therefore, any type of knowledge that is not obtained through empirical control, asserting, at the same time, a logical continuity between the natural and social sciences, with sharing of the same principle of causality.

In the early 1920s, a group of Viennese intellectuals (including mathematicians, physicists, sociologists, and economists), self-appointed as the "Vienna Circle", founded a movement that came to be known as "Neopositivism". As it developed the ideas of Comte, the neopositivist movement presented itself as being determinedly anti-metaphysic ${ }^{10}$. They considered metaphysics — especially idealistic metaphysics, which still dominated the German universities - to be a set of philosophical musings devoid of any explanatory rigor, arguing that, with the exception of mathematics and logic, only through the sciences-and especially Physics-was it possible to obtain true knowledge. Accordingly, the only way to increase the amount of reliable information available about the world would inevitably be to expand the scientific method to all other areas of knowledge, with the establishment of credible propositions justified by controlled experiments and observations ${ }^{11}$.

Despite its eccentric objectives, the neopositivist current exerted a profound influence on the scientific community throughout the Western world until the second half of the twentieth century. The natural sciences, of which Physics was the example par excellence, became the model of rationality, inevitably infecting, with this "scientific proposal of the world", the various social and human disciplines that had recently become autonomous from Philosophy.

Beginning in the 1960s, new perspectives on the Philosophy of Science brought about by intellectuals such as Popper, Quine, and Feyeraband began dethroning this anti-metaphysical movement, revealing and seeking to respond to its profound limitations (Morin, 1977; Popper, 1999). Nevertheless, the main blow to the positivist view of the world came, surprisingly, from the very science that had served as its paradigm—Physics—which early in the century saw the principles that had been bandied about by that epistemology revealed as insufficient.

\section{The Quantum Revolution}

"[The two-slit experiment] contains the only mystery. We cannot make the mystery go away by "explaining" how it works... In telling you how it works we will have told you about the basic peculiarities of all quantum mechanics."

\section{R. Feynman}

Towards the end of the nineteenth century, classical physics represented the ultimate explanatory model of all natural phenomena. In 1900, Lord Kelvin, president of the British Royal Society, went so far as to say in a speech to the British Association for the Advancement of Science that the edifice of Science was complete and that all that remained for future physicists was merely its improvement and the development of its technical applications. Only two small dark clouds could be distinguished in this idyllic panorama, and if, on the one hand, he hit the mark in their identification - that they represented relativity and quantum mechanics - on the other hand, he erred in predicting their rapid dissipation. Following these forecasts, the period of 1920-1928 is described in the history of modern science as a period of "crisis of Physics". During this period, those theories underwent explosive development, ending, finally, by imploding the structure of Classical Physics (Rosenblum \& Kuttner, 2011). This scientific revolution had repercussions not only at the level of the nature of its object but also with the logical instruments needed for scientific work—namely, concepts such as matter, space, time, and causality — which until then had been its fundamental pillars.

The fact that Physics had been established in the nineteenth century as an archetype of genuine science led to

\footnotetext{
${ }^{10}$ Metaphysics (from the ancient Greek $\mu \varepsilon \tau \alpha[\mathrm{meta}]=$ after, beyond; and $\varphi v \sigma \iota \varsigma$ [physis] = nature or physics) was conceived by Aristotle as a "primary philosophy" or "theology" as opposed to "secondary philosophy" or "physics" and is responsible for the study of the realities that lie beyond the physical realities and, therefore, appear inaccessible to scientific research.

${ }^{11}$ See the reprinting of the English translation of the manifesto of the Vienna Circle, titled "The Scientific Conception of the World", in Neurath (1973).
} 
a situation in which a crisis at its core would destroy the status acquired by science as an explanatory model of the world, thereby inevitably reviving the great eternal questions of Philosophy. In Physics, these questions found an original solution in the Interpretation of the Copenhagen School of Quantum Physics, which involved an unprecedented epistemological orientation with new scientific criteria.

\subsection{The Problem}

Until the advent of Quantum Physics in the first quarter of the twentieth century, the scientific community, and people in general, believed in causality and, therefore, in the objective reality of nature. After acceptance of the Borhean paradigm for interpretation of Quantum Physics in the famous Solvay International Conference of 1927, this way of thinking was drastically modified. Causality was considered obsolete, and objective reality was thus denied (Bohr, 1935a).

The problem that presents itself is directly related to the issue of wave-particle dualism, which is one of the fundamentals of quantum systems. At the beginning of the twentieth century, Einstein demonstrated with "his" photoelectric effect that the photon, in addition to behaving like a wave, as had been believed, could also exhibit particle-like behaviour. This duality was subsequently established for other microscopic entities, such as the electron and the atom, and eventually for all macroscopic objects (De Broglie, 1970). In the face of these contradictory results, obtained through the strict scientific method in force, it was concluded that quantum entities would have to exhibit two natures: wave and particle.

To aid comprehension of the importance and complexity of this problem, I will discuss an experiment that, according to Richard Feynman, exposes "the only mystery" (Feynman, 1965) of quantum mechanics: the double-slit experiment.

This experiment essentially consists of an isolated experimental apparatus containing a source of quantum entities S (arranged in such a way that one and only one entity is emitted at a time); a plate, placed in front of the source and where the two slits are located; and a target $\mathrm{T}$, prepared to detect the arrival of those entities (Figure 1). These experiments have been conducted with virtually all the quantum elements, from atoms to photons. In this case, to clarify the situation, let us assume that we are addressing a source of photons. This source emits these entities in such a way that only one photon is encountered at a time in the experimental device, thereby excluding, a priori, any possibility of encountering two or more photons simultaneously in the experimental device.

Our purpose now is to predict the distribution of the impact positions of the photons that, after a certain time, reach the target detector.

The photon is emitted by the source, and during its trajectory, it will encounter the plate with the two slits. The following events can occur: 1) the photon hits the plate and is absorbed-this situation is irrelevant to our prediction because the photon has no possibility of reaching the target detector; or 2) the photon passes through the slits -in this case, it will pass through the top slit or the bottom slit.

This hypothesis may well be subjected to experimental verification. To do so, one must simply replace the target detector in the previous experiment with two photon detectors, P (Figure 2), one in front of each of the slits. It can be observed that sometimes the photon is detected above and other times it is detected below. The two detectors are never activated simultaneously. Therefore, the apparently reasonable conclusion to take from this experiment is that the photon sometimes passes through the top slit, while other times it passes through the bottom one.

For this conclusion to be true, we should await the arrival of the photons in the target detector back in Figure 1 sometimes originating from one slit and other times from the other. Under these conditions, the distribution of the photon impact positions in the target detector, after a certain amount of time, will be the sum of the two distributions of the photons originating from each of the slits. The distribution of the arrival of the photons originating from a slit is a normal continuous bell-shaped distribution. This phenomenon, as expected, means that the photons are concentrated mainly in the central zone of the slit, progressively blurring as they move away from this centre.

Thus, the expected result should be the sum of two normal curves, giving origin to a curve that is also a continuous bell-type curve (Figure 3(a)). However, what this experiment shows us, without a doubt, is that the arrival distribution of the photons in the target detector, far from being a bell-shaped curve, is instead an interferential distribution with maxima and minima (Figure 3(b)). Now, as we know, the interferences result from the 


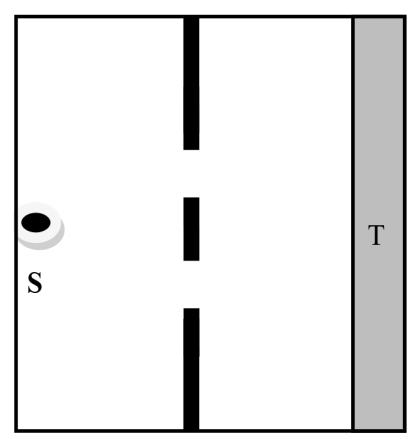

Figure 1. Experimental apparatus for the two-slit experiment.

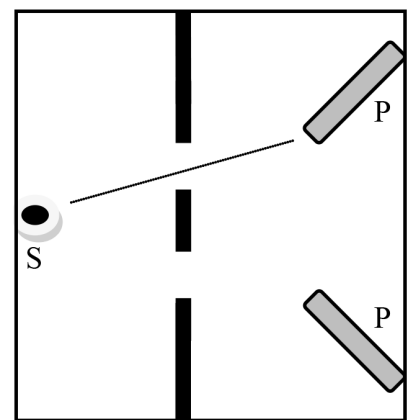

Figure 2. Double-slit experiment with two photon detectors.

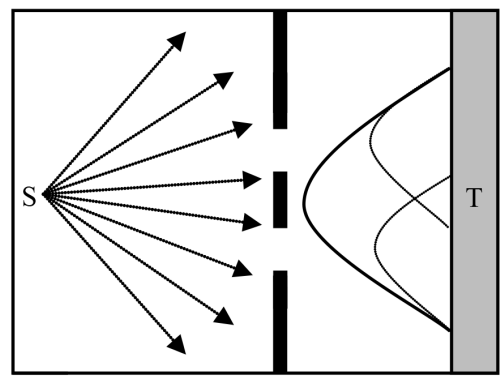

(a)
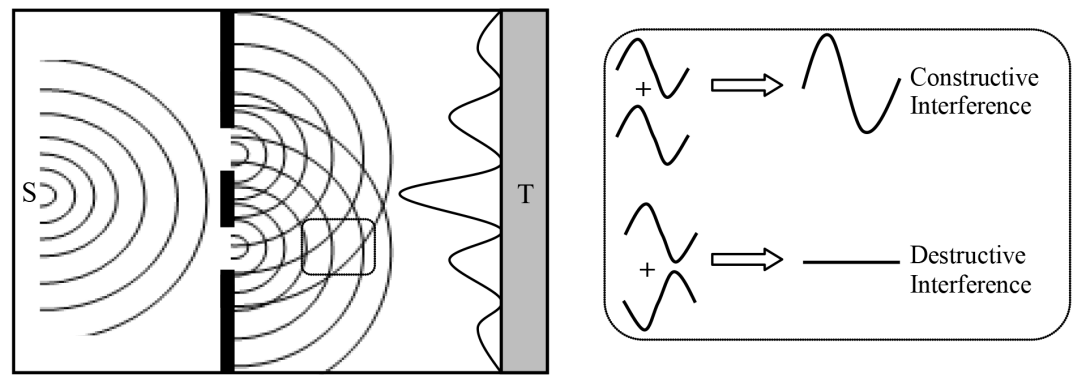

(b)

Figure 3. Results obtained in the measurement of the photon considered as a particle (a) and as a wave (b). (Explanatory detail of the constructive and destructive interference observed in the interaction between waves).

superposition of at least two waves. Therefore, we conclude that something, originating from the two slits, reached the target detector. The photon — whatever this quantum entity is—had, in a sense, to pass through both slits simultaneously, and, therefore, it must be a wave.

As seen, we are faced with a logical paradox: the photon must pass through one slit or through the other, and, 
at the same time, it must pass through one and the other. In the first experiment, with the two detectors placed in front of the slits, we saw that the photon travels through only one of the slits; in the second experiment, observation of the interferential distribution in the target detector reveals that the photon must pass through the two slits simultaneously.

Thus, the nature and the behaviour of the photon vary according to the type of experiment performed.

\subsection{Quantum Mechanics}

To reconcile the previous results, which appear to be contradictory, Niels Bohr (1885-1962), the founder of the Copenhagen school, postulated that before being measured or observed, quantum systems do not have a real and objective existence. All we have is a set of potentialities or probabilities that can eventually become real through the act of measuring (Bohr, 1935b). In the case described, before being observed, the photon is neither a wave nor a particle but rather an undefined system composed of both attributes. It "is" both wave and particle.

In the nomenclature of Quantum Physics, the photon is considered to be in a "superposition" of these two complementary states. Only when the type of experiment to be performed is decided upon does this superposition "collapse" on one of its terms. Starting from these considerations, Bohr articulated the "Principle of Complementarity", which marks the birth of quantum theory and establishes that the experimental verification of a specific aspect of a system (of atomic dimensions) inevitably destroys any possibility of investigating a complementary aspect of this same system ${ }^{12}$.

Thus, "observation" assumes a decisive role in quantum mechanics; it is responsible for the ultimate concretization of a specific and measurable attribute of a set of overlapping potentialities that exists in any reality outside our sensible world.

However, what exactly is an observation? According to the official response of Copenhagen, observation is any record of a microscopic event performed by a macroscopic measurement instrument. In 1932, some years after Bohr's Copenhagen interpretation, John von Neumann (1903-1957) developed this concept, eventually establishing the inevitability of the participation of consciousness in this process (Neumann, 1955). He followed Bohr by minimizing the influence of consciousness on the measurement of macroscopic objects, suggesting here the use of classical mechanics as a good approximation of quantum mechanics in order to avoid a more complicated mathematical formulation ${ }^{13}$.

In 1935, in preparing a response to an article by Einstein and two collaborators (Podolsky and Rosen) that asserted the incompleteness of quantum theory (Einstein, Podolsky, \& Rosen, 1935), Bohr noted, for the first time, that observation, by itself, has the ability to instantly affect a remote physical system, without any need for intermediate physical disturbances (Bohr, 1959). Aware of its philosophical nature and unable to demonstrate it experimentally, Bohr sought to defend his theory, redefining the objective of science. Rather than seek to explain nature, Bohr admits that the role of science should be to describe what can be said about nature, recalling the often-cited Wittgensteinian expression "whereof one cannot speak, thereof one must be silent" (Wittgenstein, 1922). A member of the Vienna Circle, Einstein refuted this response, stating that it was based on a "spooky action at a distance" (Einstein, Born, \& Born, 1971: p. 158).

By this time, the community of physicists, who were more interested in exploring the wide range of practical applications provided by this new theory, which was shown to be infallible, were not interested in these philosophical trifles, keeping their distance from this controversy. Only in 1965 was this "philosophical question" treated in the "most profound scientific discovery of the second half of the twentieth century" (Whitaker, 1998) -Bell's theorem. Based on the principles that our world exhibits real physical properties that are not created by its observation ("reality") and that objects can be individualized one from another so that what happens to one does not immediately affect the other ("separability"), John Bell (1928-1990) mathematically derived his "inequality” (Bell, 1964).

If, in controlled experiments, Bell's inequality had been shown to be false in any situation, one or both of the premises that logically led to its establishment would, necessarily, also be false. These experiments were conducted a few years later by Freedman and Clauser (1972) and Aspect, Grangier, and Roger (1981), and Bell’s

\footnotetext{
${ }^{12}$ A corollary of this theorem is Heisenberg's Uncertainty Principle, which admits the impossibility of simultaneous determination of both momentum (the product of mass and velocity) and position for any quantum entity (Heisenberg, 1999).

${ }^{13}$ The discussion of the phenomenal substantiation of macroscopic objects is outside the scope of this article. In general, it is considered, for all practical purposes, that given their sizes, these objects cannot be isolated from the rest of the world and, thus, are permanently under some form of “observation”.
} 
inequality was in fact violated as expected and in accordance with the premises of quantum theory. Thus, it was scientifically proven that our world —and the objects in it—lacks both reality and separability, and thus, shows itself to be an unreasonable world.

Bell's theorem therefore gives us the idea of a microscopic quantum world in which what occurs at one location can instantly affect occurrences in a distant place- even without physical forces connecting the two elements. Designated by Bohr as an "influence", this property is currently known as "entanglement” (Jaeger, 2009) and assumes that any objects that have ever interacted are forever entangled, and thus that what happens to one will instantly influence the other, even if the two are located in different regions of the universe.

\subsection{Implications}

Since its conception, Quantum Physics has been claimed to be the most accurate theory ever. Equipped with high mathematical rigor, it has offered infallible predictions of the results of thousands of experiments, replacing traditional Classical Physics as the regulatory mechanics of the world. However, despite its practical success, it is still in essence a mysterious theory, causing consternation due to the incongruity between its premises and our daily sensory experience.

We have found that indeterminism reigns in the quantum world. In its stochastic mechanics, we can never predict which of its possibilities will be realized. The answer obtained when we investigate a system depends on how we pose the question—producing as many answers as there are ways to measure a system.

The quantum world is, as seen in the double-slit experiment, an isolated system, which implies an imperviousness to physical interactions with the "outside world". The only form of communication with that world is established through the observer's consciousness. It is the decision of the investigator, based on the type of measurement to be made, which type of experimental apparatus to use, et cetera, which allows the "selection" of one of several overlapping potentialities, from the microscopic quantum world to our world. Only after being introduced to this classical existence, through observation, does this probability acquire a defined value, which will always depend on the consciousness of the investigator. Through this process of "realization" performed by the reflective consciousness - with the concretization of indeterminate elements from the quantum world-the observer will subsequently be able to assign a meaning to that which is observed, integrating it with other meanings and, eventually, establishing a theory.

The object of Physics, therefore, ceases to be objective, becoming the nature of the relationship of the quantum world with the investigator.

Based on the above, we find that quantum mechanics subverts many of the fundamental concepts of Classical Physics. We have demonstrated what it does with the principle of causality, with the notion of matter and, through the non-local nature of entanglement, with space. However, what occurs in relation to time? What is quantum temporality like?

We saw earlier that the quantum system represents an indefinite reality of various overlapping potentialities "waiting" for an observation that concretizes one of them and, subsequently, records it in the sensible world. However, in accordance with the conceptions of the macroscopic world, the observed object only begins its existence after being measured. We cannot assign a past to it because it did not exist before as a defined entity; it was merely a potentiality, among others, in a world with physical properties different from the classical world. Thus, we see here a strange reversal in temporal progression, in that the history of that which we measure is constructed retrogressively from the time of the measurement by a conscious observer. In the case of the double-slit experiment, only after we have established the particle nature of the photon can we infer its behaviour, in particular that it will have passed through one of the slits and reached one of the detectors instead of behaving like a wave.

Our classic concept of time is thus also subverted by quantum mechanics. There will certainly be a "temporality" inherent to the isolated quantum system; however, that temporality has no relation to the temporality by which we conduct our daily lives.

Very attentive to the scientific advances of his time, Henri Bergson (1859-1941) ${ }^{14}$ predicted this quantum revolution in his philosophy, proposing, before Bohr, a redefinition of the existing concepts of time and space. We discuss his fundamentals below.

\footnotetext{
${ }^{14}$ French philosopher, winner of the Nobel Prize for Literature in 1927.
} 


\section{Bergson’s Response}

"Questions relating to subject and object, to their distinction and to their union, should be put in terms of time rather than space.”

\section{H. Bergson}

According to Henri Bergson, the previous difficulty in understanding the temporality (and the existence) of the photon before its measurement is the result of a bias in the way we understand time. Ultimately criticizing Einstein (Bergson, 1965), Bergson argues that mathematical time is nothing but a fourth dimension of space. In their mathematical analysis, physicists forcibly divide time into measurable portions, thus breaking its continuity and immanence ${ }^{15}$. Projecting time into space, they define a static temporality consisting of juxtaposed symbolized elements, which, by themselves, are devoid of any qualitative attribute. In this spatialized time, moments are distinguished only by their numerical quantity and by the space occupied by each one, not by their qualitative nature. Showing itself to be a homogeneous succession of moments, this time displays scientific utility, which makes it possible for predictive laws to be formulated from it, which will invariably be shown to be valid in both past and future senses.

For Bergson, this “clock-based” time is a false time-instead, real time exists prior to its spatial symbolization and extension. Following in the footsteps of Kant, Bergson believed that the only way of expressing this genuine temporality is in the individual inner experience, conceiving temporality, therefore, as a pure duration, in which: "Pure duration is the form which the succession of our conscious states assumes when our ego... refrains from separating its present state from its former states” (Bergson, 1888: p. 100).

Consisting of temporal mnesic elements, Bergson's duration appears as a continuous flow of memories in constant update. Here, its elements are not juxtaposed and individualized; rather, they take on a virtual form, arranged in a dynamic interpenetration of an indivisible and qualitatively heterogeneous whole. As in the melody that we recall having heard the day before, in duration,

"There is a succession of states, each of which announces that which follows and contains that which precedes it. They can, properly speaking, only be said to form multiple states when I have already passed them and turn back to observe their track. Whilst I was experiencing them they were so solidly organized, so profoundly animated with a common life, that I could not have said where any one of them finished or where another commenced. In reality no one of them begins or ends, but all extend into each other.” (Bergson, 1903)

Thus, in Bergson's thinking, a duality is established in which time and space are assumed to be antagonistic existential elements. Space shows properties of extension and materiality, characterizing itself by its homogeneity, measurability, and static and quantitative relationships. Defined as duration, time is on the contrary shown to be a heterogeneous and indivisible element and, therefore, immeasurable.

However, unlike the Cartesian duality, this duality does not entail incommunicability. We see how, aiding himself with the image of the cone, represented in Figure 4, Bergson illustrates the interaction between these two elements of our existence.

In this image, a plane and an inverted cone whose apex is part of that plane are represented. The plane, designated "plane P" by Bergson, is the "plane of my actual representation of the universe” (Bergson, Paul, Palmer, \& Jelliffe, 1896: p. 196). The cone "SAB" symbolizes the past-a memory of the duration-in which its base “AB” represents its most remote region, consisting of a set of neutral memories, devoid of any personal reference. As we descend, we pass through an “indefinite number” of different regions of the past—planes A'B' and A"B"-formed by our personal representations and ordered by their distance from or proximity to the present. At the vertex of the cone, "S", we have the image of our own body, concentrated on a point in the present. This vertex falls within the plane, implying that the image of our body "participates in the plane" of our current representation of the universe. In this scheme,

“...my present consists in the consciousness I have of my body... [My body] represents the actual state of my becoming, that part of my duration that is in the process of formation. More generally, in that continuity

\footnotetext{
${ }^{15}$ In this article, the concepts "transcendent”, “transcendental”, and “immanence” in the Kantian conception (2007/1781) are used. Transcendent refers to what is beyond experience and is, for this reason, unattainable knowledge; transcendental knowledge refers to the concepts that are given to us a priori, in a universal way, and independent of our experience; immanent reality is contained in the daily empirical experience of the individual in the world.
} 


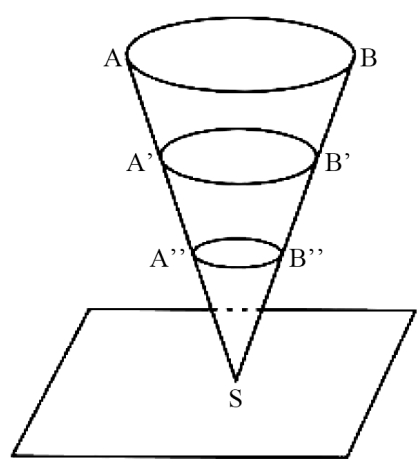

Figure 4. Image of the cone.

of becoming, which is reality itself, the present moment is constituted by the quasi-instantaneous section effected by our perception in the mass that is in the process of flowing, and this section is precisely what we call the material world.” (Bergson et al., 1896: p. 177)

By stating that the present is "the quasi-instantaneous section" in the "continuity of becoming, which is reality itself”, Bergson takes an unprecedented step in the entire history of philosophy, attributing the reality of the Being (and the world) to its temporality. In the thinking of Bergson, only time is real. However, present time is not addressed here-it is only a brief passing moment, a moment spatialized in a "material world", which, when perceived, has already passed. Rather, reality concerns the memory of the Being. Here, the present is a function of the past, and consciousness is a function of unconsciousness ${ }^{16}$.

The figure of Bergson's cone symbolizes, therefore, a dynamic process in which not only does the apex of the cone advance towards the plane under the constant pressure of an élan vital ${ }^{17}$ but also the plane of the conscious representations insinuates itself, at all times, on the cone, thus leading to a creative dialectic tension between these two elements. In the words of Bergson:

"Duration is the continuous progress of the past which gnaws into the future and which swells as it advances. And as the past grows without ceasing, so also there is no limit to its preservation ... In its entirety, probably, it follows us at every instant; all that we have felt, thought and willed from our earliest fantasy is there, leaning over the present which is about to join it, pressing against the portals of consciousness that would fain leave it outside. The cerebral mechanism is arranged just so as to drive back into the unconscious almost the whole of this past, and to admit beyond the threshold only that which can cast light on the present situation or further the action now being prepared-in short, only that which can give us useful work. At the most, a few superfluous recollections may succeed in smuggling themselves through the half-open door. These memories, messengers from the unconscious, remind us of what we are dragging behind us unawares... Doubtless we think with only a small part of our past, but it is with our entire past, including the original bent of our soul, that we desire, will and act.” (Bergson, 1911: p. 9)

We see, therefore, that in the philosophy of Bergson, the key role is given to the unconscious. In this duration, we constantly “jump” (Bergson et al., 1896: p. 188) in an instantaneous way (d'emblée) from our present spatialized condition to a non-spatial past. This is, initially, a "general past", conceived by Bergson as an ontological and pre-psychological element - an eternal and passive past, which makes possible all the specific pasts (Deleuze, 1988). In it, pure singularities (Bergson et al., 1896: p. 281) are contemplated, which are subsequently subjected to a process of psychologization in interactions with the memories and emotions of a particular plane of the psychological unconsciousness. Only then does this stream of images become entangled with the personal psychological representations and enter into "coalescence" with the present.

In a circuit with the present, these representations exert a constant pressure to become incorporated. Here, the

\footnotetext{
${ }^{16}$ Bergson here restricts the concept of "consciousness" to the present moment that is spatialized and dependent on the body, which broadens the concept of "existence" to the set of conscious and unconscious elements.

${ }^{17}$ Julian Huxley refers to this creative principle as follows: "When I was just last in New York, I went for a walk, leaving Fifth Avenue and the Business section behind me, into the crowded streets near the Bowery. And while I was there, I had a sudden feeling of relief and confidence. There was Bergson's élan vital — there was assimilation causing life to exert as much pressure, though embodied here in the shape of men, as it has ever done in the earliest year of evolution: there was the driving force of progress” (Huxley, 1899-1980: lecture 1).
} 
resistance imposed by our body is essential to avoid being flooded by useless or even disastrous memoriesacting as a "central telephone switchboard", our brain only materializes those representations that interest the present calls, repressing all the others. Because of the various possibilities for action available to it, our body is constituted according to Bergson as a "zone of indetermination" (Bergson et al., 1896: p. 23), with its nervous system responsible for communication with the unconscious mind and determination of the representations appropriate for the present needs and functions. It is this adaptation of the past to the present in the dependency of a motor ally that Bergson calls "attention to life” (Bergson et al., 1896: p. 226).

\subsection{The Double-Slit Experiment Revisited}

We are now in a position to describe the double-slit experiment in the terms of Bergson.

Thus, faced with the present need to observe the nature of a photon, which prior to its measurement displays a pure undefined nature, the experimenter runs a device that, similar to the human brain, inevitably establishes, depending on its structure and composition, a certain type of behaviour for the entity being evaluated, in a manner that satisfies the initial need.

Accordingly, this experimental apparatus is a model of its ontology, in which the photon beam represents the continuous flow of passive singularities originating from the ontological unconsciousness, and the very disposition of the apparatus - situation A or B-is a present contingency, configured for the measurement of a certain property of an "undefined" photon. Here, the reading of the results obtained by an external observer will inevitably involve the translation of the symbol displayed by the detector - in this case, the pattern obtained — which involves recourse to an intelligence specialized in the interpretation of these signals. At this precise moment, the temporality of the photon is broken, and any knowledge sought of its history will inevitably have to be inductive and, apparently, regressive.

Thus, for centuries, it was believed that the nature of light was only wavelike because whenever a certain type of experiment was performed (situation B), an interference pattern that was known to be associated with a wave nature was inevitably recorded. Only when the same quantum element is subjected to a new experiment- - that is, when the present experimental contingency is modified in a way to allow the measurement of a complementary nature of this same element-do we face an apparent paradox of a prior superposition of logically incompatible natures.

For expository simplicity, it was decided to present the basic fundamentals of quantum theory starting from a simple system with a single element. However, in complex states, with more than one "entity" in the same system, as with the unconscious duration, we inevitably must consider the interaction between the elements, anticipating that the insinuation of a certain psychological state varies as a function of how it is interpenetrated (in time) to the other states ${ }^{18}$.

\subsection{Intuition vs. Intelligence}

Despite its simplicity, this scientific experiment shows us the limits of science itself. It reveals to us how, in our spatialized conception of the world, we continuously take the Being as the being consciously perceived. Deluded by our sense perceptions and looking for the comfortable safety of a deterministic world, we take the part for the whole, the contingent for the real. We unveil the object taking an interested position, obscuring what is not of interest. In doing so, we neglect the unconscious aspects of our existence, which at any moment bring change and ontological novelty to our existence.

Another inference to derive from this experiment is that, upon reaching the limits of physics, we are inevitably confronted with an inaccessible meta-physical reality that is immune to logico-scientific analysis-the current instrument of choice for studying the world. If we characterize ourselves by rationality and we think through a material brain, can we ever reach the reality of our Being, our duration? Here, it seems obvious to answer negatively, as Kant did when he could not apply his categorical principle.

In contrast, Bergson distinguishes, in addition to analytical intelligence-a feature of science and logic - another way of obtaining knowledge: intuition. Unlike intelligence, which is directed towards action through the analysis of spatial symbols and objects, intuition is an immediate, non-utilitarian, and disinterested knowledge of

\footnotetext{
${ }^{18}$ In Quantum Physics, the dynamics of these pre-measured quantum systems is currently described by the famous Shrödinger equation (Schrödinger, 1995).
} 
the world. This form of knowledge is not directed towards survival and adaptation to the world; rather, it seeks to establish a sympathy with it by capturing the duration within its interior ${ }^{19}$. Bergson distinguishes these two instruments for obtaining knowledge as follows:

"By intuition is meant the kind of intellectual sympathy by which one places oneself within an object in order to coincide with what is unique in it and consequently inexpressible. Analysis, on the contrary, is the operation which reduces the object to elements already known, that is, to elements common both to it and other objects. To analyse, therefore, is to express a thing as a function of something other than itself. All analysis is such a translation, a development into symbols, a representation taken from successive points of view... In its eternally unsatisfied desire to embrace the object around which is compelled to turn, analysis multiplies without end the number of its points of view... and ceaselessly varies its symbols that it may perfect the always imperfect translation. It goes on, therefore, to infinity. But intuition is possible, is a simple act...” (Bergson, 1903)

Overcoming the categorical limitation of Kant, Bergson states that knowledge of our duration is possible through intuition ${ }^{20}$. Only through this intuitive knowledge is it possible to capture the whole of our personality in its temporal evolution - our real existence. Bergson warns, however, that this form of metaphysical knowledge brings with it a particular difficulty in terms of its concretization, given that our entire body —and our senses in particular-is configured for analysing and dividing the world to take from the world what can satisfy its vital needs.

For Bergson, intuition is a refinement of instinct, with the latter being the former's basic element. However, although intuition is derived from instinct, it is not accessible to other animals. Only in man can this intuition lead to an "intellectual sympathy" because man is the only intelligent being that exists. For instinct—and, therefore, intuition - to become disinterested, it must coexist with intelligence. Only through this association can this disinterested knowledge become self-conscious, thus expanding conscious knowledge to the unconscious.

Given the very non-spatial and supra-personal nature of the psychological unconsciousness, it is not surprising that Bergson responds to the problem of "entanglement" assuming instantaneous connections not only between the elements of a particular unconsciousness but also among the various particular unconsciousnesses, in a collective biological memory: "We trail behind us, unaware, the whole of our past... Thus the instinctive knowledge which one species possesses of another on a certain particular point has its roots in the unity of life, which is, to use the expression of an ancient philosopher, a 'whole sympathetic to itself."” (Bergson, 1911: p. 67)

Thus, through intuition, it becomes possible to have not only sympathy with our duration but also, subsequently, with other durations, gathering in a particular consciousness an endless number of influences originating from all the points of the universe (Bergson, 1903). Here, as in the quantum systems, it is anticipated that this sympathy among interpersonal unconscious elements varies in direct proportion to the intensity of their previous encounters.

\subsection{Bergson's Legacy}

Henri Bergson was a strong critic of the assumptions of positivist epistemology from the late 1800s to the early 1900s. He criticized the associationist Psychology of his time for being subject to the methods of the natural sciences and attributing a symbolized phenomenal nature to the states of consciousness. Taking time for space, this psycho-physical determinism presupposed the establishment of a strict parallelism between psychic life and the brain and the determination of an alleged physical cause of psychological phenomena through its quantification.

\footnotetext{
${ }^{19} \mathrm{We}$ can see this concept of $\sigma v \mu \pi \alpha \theta \varepsilon \mathrm{\varepsilon} \alpha$ (sympathéia) in the works of many thinkers throughout the history of Philosophy. In the thinking of Plotinus (204-270 A.D.), for example, sympathy is conceived as a transfer of movement or inner feeling between objects (not necessarily conscious beings) seeking a universal harmony: "now, if the vibration in a lyre affects another by virtue of the sympathy existing between them, then certainly in the All—even though it is constituted by contraries - there must be one melodic system” (Plotinus, 2004: p. 387).

${ }^{20}$ Despite his Kantian roots, Bergson's philosophy conceives "intuition” differently from that of Kant. Instead of a mere faculty for perceiving outside of the senses or consciousness, for Bergson, intuition is conceived as a deep "reflection" that establishes direct contact with reality, before any appeal to the faculties of reason, and beyond language. Surprisingly, in the development of the notions of Kant, Bergson approaches the Cartesian formulations. In his ontological argument, Descartes accepts a way of grasping reality more intuitively than rationally it no longer comes from me, that I have the idea of God, but rather the idea of God that is within me (Descartes, 2010: fifth meditation). Thus, like Bergson, Descartes, with his cogito ergo sum, proposes that the discovery of the ontological domain is made through metaphysical intuition, which addresses a being and not a mere object, instead of a mere rational processing (Huisman \& Vergez, 1976).
} 
Bergson refutes this physiological psychology, arguing that by the very nature of its object, Psychology must, inevitably, extend beyond the material, resorting to intuition as the only form of knowledge of the real world.

Despite attributing the knowledge of reality to intuition only, Bergson does not deny the importance of intelligence and positivist science, attributing to them a fundamental ability to practically adapt to the demands of the material world. Thus, he proposes, instead of subjecting one of these modes of knowledge to its complementary, redefining Psychology by integrating both into its method.

Throughout the twentieth century and despite initial enthusiasm, Bergson's philosophy was overshadowed not only by the great influence of positivist epistemology but also by the unstable socio-political climate of this historical period. Nevertheless, throughout the evolution of quantum theory, various eminent physicists, such as De Broglie (1947) and Capek (1969, 2012), demonstrated the parallelism between the ideas of Bergson and quantum mechanics. Even recently, using the concept of Bergsonian time, Antoniaou and Christidis (2010) derived a mathematical formula that enables the description of the irreversibility of physical processes.

However, it was not only in Physics that the influence of Bergson was felt. Subsequently, in Dynamic Psychiatry and, specifically, in Psychoanalysis, this new theory of the unconscious also exerted a profound influence, as we shall see below.

\section{From Janet to Bion}

“An emotional experience cannot be conceived of in isolation from a relationship.”

\section{W. Bion}

At the turn of the twentieth century, Pierre Janet was the acknowledged leader of Dynamic Psychiatry. Having been Bergson's colleague at the École Normale Supérieure, Janet had a close collegial relationship with this thinker throughout his life, which provided a mutual intellectual influence in the works of both. We can see this influence in the similarity of the Janetian concepts of psychological tension (tension psychologique) and the function of reality (fontion du réel) to Bergson's aforementioned philosophical formulations relating to the attention to life (Ellenberg, 1970).

In his formulations, developed through the observation and treatment of neurotic patients, Janet understood the adjustment to reality as being possibly the most difficult task of human existence. In a healthy mind, this effort involves a psychological tension that is maintained and develops, constantly, in the encounter with reality. However, in situations surrounded by vehement and insurmountable emotions, this tension breaks down, and the individual inevitably experiences an “abaissement du niveau mental” (Janet, 1903).

While visiting Paris in 1885, Sigmund Freud (1896a) adopted many of these ideas and even incorporated them into his "Studies on Hysteria". Here, along with Breuer, he acknowledges the existence of the Janetian idées fixes, conceived as traumatic experiences dissociated from conscious perception, establishing, later on in 1896, the "Theory of Seduction" in which he postulates that the existence of a "precocious experience of sexual relation... resulting from sexual abuse committed by another person... is the specific cause of hysteria... not merely an agent provocateur»"21. Just a few years later, discovering that these experiences may not have been only imaginary but also inadvertently suggested by him to his patients, Freud reinterpreted his findings with the assumption of a biological and constitutional infantile sexuality responsible for the construction of a set of intrapsychic fantasies that would subsequently be repressed at an unconscious level (Freud, 1905).

In this conception of the unconscious, Freud separates himself from Janet and establishes his own movement, which he refers to as Psychoanalysis; in it, he advances the study of specific fantasies from an unconscious psychic world of biological roots. In this step, he necessarily relegates the interaction with the outside world to a secondary plane of importance.

We will be able to better understand this choice of a positivist justification of the mind if we consider Freud's biography and specifically academic training prior to meeting the dynamic French psychiatrist. During this period, some of the exponents of positivism were Freud's teachers in Vienna. It was Ernst Wilhelm Von Brücke (1819-1892), the most eminent representative of positivism in Vienna, who placed a microscope in front of Freud and tasked him with the study and microscopic observation of the histological structure of the nerve cell (Assoun, 1981: p. 104). These positivist models marked all of Freud's work, which sought to claim Psychoanalysis as a scientific discipline, based on the existing medical model. We can see this epistemological attitude

\footnotetext{
${ }^{21}$ In fact, Freud defines these premature sexual experiences as the etiological element not only of hysteria but also of the neurosis of obsessions and, possibly, of "various forms of chronic paranoia and other functional psychoses” (Freud, 1896c: p. 219).
} 
throughout his work in statements such as: "Analysts are at bottom incorrigible mechanists and materialists" (Freud, 1921: p. 179). Indeed, in his autobiography, Freud acknowledges constructing his theory by disregarding any philosophical foundation (Freud, 1924: p. 59) and believing that, eventually, even his metapsychological considerations, which were considered speculative, would be underpinned by future neuro-anatomo-physiological knowledge (Freud, 1914: p. 78).

Thus, despite his contact with the contemporary Bergsonian philosophy, particularly through James Putnam ${ }^{22}$, Freud proved uncompromising in his convictions, defending the naturalistic study of the mind until the end of his life and even becoming a member of the Vienna Circle in the $1920 \mathrm{~s}^{23}$.

Regardless of Freud's imperviousness to Bergson's ideas, the same did not occur with the person who, at one point, Freud considered his most brilliant follower-Carl Jung.

Although their intellectual paths crossed between 1907 and 1913, Freud and Jung started from very different epistemological positions. If Freud's starting point was positivist, Jung, in his student days, showed an interest in Vitalism as an intermediate solution between the metaphysical and positivist extremes (Jung, 1896: para. 63). Thus, as early as 1896, in his Zofingia Lectures, Jung defended the existence of a vital principle that,

"governs all bodily functions, including those of the brain, and hence also governs consciousness... The vital principle extends far beyond consciousness in that it also maintains the vegetative functions of the body which, as we know, are not under our conscious control. Our consciousness is dependent on the functions of the brain, but these are in turn dependent on the vital principle, and accordingly the vital principle represents a substance, whereas consciousness represents a contingent phenomenon.” (Jung, 1897: para. 96)

Later, after contact with and practice of the psychoanalytic method, he noted the insufficiency of this approach, particularly in the explanation of psychotic phenomena observed in his schizophrenic patients in the Burghölzli Psychiatric Hospital. Thus, Jung inevitably broke away from Freud, transposing his psychophysical determinism and developing a more comprehensive theory of the mind, with vitalist inspiration, that would include even patients with more severe psychopathologies ${ }^{24}$.

In 1914, Jung accepted the similarities between his formulations and Bergson's theory:

"I realize that my views are parallel with those of Bergson and that in my book [The Psychology of the Unconscious], the concept of the libido which I have given is a concept parallel to that of 'élan vital'; my constructive method corresponds to Bergson's 'intuitive method'. I, however, confine myself to the psychological side and to practical work. When I first read Bergson a year and a half ago I discovered to my great pleasure everything which I had worked out practically, but expressed by him in consummate language and in wonderfully clear philosophical style.” (Jung, 1914: p. 351)

This parallelism between the theories of Jung and Bergson is not a total coincidence if we consider not only Jung's early interest in Vitalism (originating largely from his training at the University of Basel, which had recently had Friedrich Nietzsche as a professor [Evans, 1979: p. 46]) but also the influence exerted by Janet in the semester that Jung spent studying in Paris in 1902-03.

In fact, in parallel with the developments of Bergson's theory, Jung constructed, through observation of his patients, an unprecedented theory of the mind that associates Janet's concepts of the function of reality and psychological tension with the implications of a Bergsonian élan vital.

Thus, in contrast to the merely sexual Freudian libido, for Jung, libido is regarded as a vital principle in general, which has its origin in what he designated collective unconscious. Instead of the personal unconsciousconceived as analogous to the Freudian unconscious - consisting of complexes representing individual experiences

\footnotetext{
${ }^{22}$ James Jackson Putnam (1909-1910), a medical neurologist at Harvard and openly Bergsonian, tried to convince Freud of Bergson’s ideas, even publishing an article entitled "Personal impressions of Sigmund Freud and His Work" in the 1909-1910 edition of The Journal of Abnormal Psychology. In this article, after characterizing memory as a vital force, Putnam substantiates its decisive influence on our perceptual representation of the world. We now know that Freud had contact with this article as a result of an analysis of his correspondence with Jung between January 10 and 13, 1910 (McGuire, 1974).

${ }^{23}$ In his "Elementary Lessons on Psycho-analysis", published posthumously, Freud asserts "Psychology, too, is a natural science. What else can it be?” (Freud, 1940: p. 282).

${ }^{24}$ Ernest Jones described this situation as follows: “As early as 1909 Jung was complaining to Freud about his difficulty in explaining to his pupils the concept of libido and begged him for a fuller definition. Freud tersely replied that he could give no clearer one than he had already Only two years later Jung equated the concept with Bergson's élan vital, with life energy in general, and thus robbed it of its distinctive sexual connotation” (Jones, 1955: p. 317).
} 
either forgotten or repressed, this collective unconscious presents a supra-personal nature, emitting universal elements that are common to all men, everywhere, that were never before conscious. These elements, designated by Jung as archetypes, establish templates through which psychic energy is organized in a way that is recognizable by the mind. Here, the archetypal representation in images and symbols is integrated into the individual psychological structure, eventually being responsible for modulating all human activity, from instinctive phenomena to reasoning and more elaborate behaviour.

Assigning a transcendental nature to the archetypal unconscious, Jung clarifies the difference between archetypes as such and archetypal images:

"The archetypal representations (images and ideas) mediated to us by the unconscious should not be confused with the archetype as such. They are very varied structures which all point back to one essentially 'irrepresentable' form. The latter is characterized by certain formal elements and by certain fundamental meanings, although these can be grasped only approximately. The archetype as such is a psychoid factor...

It does not appear to be capable of reaching consciousness.” (Jung, 1947: para. 417)

Through its representative capacity, the mind establishes a mediation between the world of universal "irrepresentable” potentialities and the subjective psychological world. Established as indeterminate patterns, images, or ideas, Jung's archetypes are only actualized through the action of an ego, when constellated in a complementary external experience (Jung, 1953: para. 845).

Now, the choice of a potentiality implies that for the same existential situation there should be at least two alternatives. In fact, one of the fundamental ideas of Jung's theory is of an archetypal organization in coniuntio oppositorium (Jung, 1963). Accordingly, the collective unconscious consists of a "living tissue" densely organized with objective and universal dualities. Only after its submission to a conscious ego, due to the practical need for unambiguous and clear decisions in everyday experience, does this ego necessarily "opt" for the specific actualization of one of these opposite potentialities of action. Thus, in Jung's words, "there is no consciousness without discrimination of opposites” (Jung, 1938: par. 178) ${ }^{25}$.

Despite recurring to an immaterial unconsciousness, Jung attributes a decisive importance to the ego in human existence and, in particular, in maintaining healthy mental functioning. To this element falls the responsibility of resisting and processing the archetypal flow to which it is constantly exposed, under the risk of inundation (= “engulfment”, “possession”) or identification (= “inflation”) with these elements and, thus, entry into a psychotic state ${ }^{26}$.

Thus, Jung takes a decisive step in Depth Psychology by substantiating the interaction of the archetypal contents of a universal collective unconscious with the personal history of the individual. He argues that since the beginning of life, the emergence of the ego and the development of the personality have resulted from the interaction of objective archetypal potentialities with the set of all individual experiences-present or forgotten. However, despite recognizing the importance of early individual experiences in mental development, Jung neglects the study of these experiences in favour of more mature and complex states of mental functioning, such as creative thinking and symbolic activity. This neglect leaves a gap in his theoretical formulations regarding how "the conscious rises out of the unconscious like an island newly risen from the sea" (Jung, 1928a: para. 103) in the first years of life, especially in the early interactions of infants with their surroundings, and how, subsequently, these experiences are manifested in the therapeutic relationship between analyst and analysand.

Unexpectedly, this gap is filled by Psychoanalysis itself through the developments of the British School of Object Relations, which had specialized in the observation of infants and children.

\subsection{Bion and the School of Object Relations}

Drawing on the Freudian developments, Melanie Klein made important contributions to psychoanalysis concerning

\footnotetext{
${ }^{25}$ After being affirmed in the Complementarity Principle of Bohr, this discrimination of opposites is later updated in the field of Physics by Wolfgang Pauli —a physicist awarded the Nobel Prize in 1945 — when he clarifies that when we opt for knowing "which aspect of nature we want to make visible... we simultaneously make a sacrifice, ... [a] couple of choice and sacrifice” (Heisenberg \& Casimir, 1974: p. 35).

${ }^{26}$ To distinguish neurotic from psychotic disorders, Jung assumes in the former a struggle for supremacy of the ego in the subjugation of the unconscious forces. "But a patient who allows himself to be swayed by the intrusions of strange contents from the unconscious, a case that does not fight, that even identifies with the morbid elements, immediately exposes himself to the suspicion of schizophrenia. His abaissement has reached the fatal extreme degree, where ego loses all power of resistance against the inimical onslaught of an apparently more powerful unconscious” (Jung, 1939: para. 516).
} 
early mental organization in the first years of life. She did so by observing infants and children, applying a play-technique conceived via an analogy with free association. In her research, she observed the early defence mechanisms used by children in their daily experiences and, specifically, in interaction with their mothers, when faced with states of excessive emotion, such as anger, hatred, anxiety, and other forms of mental disintegration. In all the strategies described, a particular highlight is the projective identification mechanism through which the infant evacuates these intolerable anxieties on the figure of his caregiver, seeking immediate relief and the obtainment of an emotional state that allows his psychological development (Klein, 1996: p. 8).

If this early stage of mental development goes well, then the infant reaches a more mature form of perception of the world, moving from a schizoid-paranoid stage-characteristic of a fragmented experience of the world consisting of separated partial objects - to a depressive position in which the infant is already able to integrate the opposing aspects of the object into a coherent whole. Thus, instead of a good breast that feeds and a bad breast that deprives, the infant recognizes the two aspects of the same breast, which is neither good nor bad but rather both (Klein, 1996: p. 14-15).

Following the Freudian tradition, Klein assigns an innate instinctive basis to the infant's early anxieties in the form of a death instinct, thus maintaining that all this early psychological development takes place in an inner world inhabited by omnipotent fantasies as an intrapsychic narcissistic process (Meltzer, 1978).

Despite this connection to Freud's positivism, Klein's work nonetheless represents an approach to analytical psychology. Like Jung, Klein moves away from Freud, formulating a mother-based psychology founded on the existence of pre-experiential dualities—good object and bad object—which model all the infant's experiences in interacting with the environment in general and the mother in particular.

Despite this Kleinian touch, the definitive break of Psychoanalysis with its positivist foundation occurs with Wilfred Bion, one of the most promising disciples of Klein. As Jung did, this psychiatrist began his career with psychotic patients by observing states of mental (dis)organization characterized by underdeveloped defence mechanisms and a compromised ability to grasp reality. Thus, from an early age, Bion was interested in understanding how we develop (or do not develop) a mental apparatus that allows us to apprehend the sensory impressions (internal and external) to which we are exposed from the first moments of life.

Unhappy with the mechanistic nature of the Freudian and Kleinian theories, Bion developed these models constructing a theory of thought based on the early relationship between mother and infant and on the existence of a transcendent reality that he called the "O"27.

Like the Jungian collective unconscious, Bion conceived the "O" as the "ultimate reality" (Bion, 1970: p. 26) that underlies all forms of thought, and, in particular, the universal thematic manifestation of myths. For Bion, "the Oedipus myth, and the elements that in the Christian religion touch on paternity and sonship both have a configuration suggesting an underlying group of which these elements are representative.” (Bion, 1970: p. 81). Here also, the similarity between the concept of "underlying configurations" and Jung's archetypes is undeniable. The $\mathrm{O}$ therefore represents a source of objective and pre-symbolic proto-emotional phenomena that at all times reach the mind of the individual and seek to be incorporated and symbolized in a thinkable form. This symbolization process occurs via an "alpha function", which processes and transforms these raw elements into "alpha elements". In this process, the emotional experience associated with those elements is surrounded by comprehensibility and meaning, and the production of thinkable elements-visual, auditory, and olfactory impressions-is susceptible to storage in the memory and use in dreams and unconscious waking thought. In other words, the alpha-function transforms the unthought emotional experience into thought. When this function is compromised, those experiences remain in the mind of the individual as unthinkable elements, as "thoughts without a thinker", designated by Bion as "beta-elements" (Bion, 1962: p. 83).

Applying these notions to the first years of a child's life, Bion describes how the infant constructs a thinking mental apparatus in the interaction with the mother. In the first moments of life, devoid of an apparatus that allows him to think the raw elements coming from the $\mathrm{O}$ and also devoid of a mature and competent alpha function,

\footnotetext{
${ }^{27}$ After the shortcomings of the assumptions of various philosophical schools in substantiating their observations—namely, logical positivism—Bion adhered, like Jung, to a neo-Kantian solution with a strong vitalistic slant taken perhaps from his recent time in Poitiers studying French literature. In the preface to their book, the Symington \& Symington (2002) describe one of the various seminars given by Bion as follows: "We all desire to exist, said Bion in a seminar. Life, said Bergson, is the tendency to act on matter. Human beings have evolved from apes, apes from monkeys, monkeys as a branch of mammals, mammals from reptiles and so on. Evolution marks the path along which the élan vital has travelled in its journey. Human beings are not the finished product; the élan vital is still in process. When we have demonstrated the pathway, we have not explained life itself. The pathway has an identity in virtue of a chain of causal connections, but these do not tell us about life itself. Life thrusts we know not where."
} 
the infant has no other solution than to evacuate these intolerable elements onto the people in his surroundings, particularly his mother. When this process occurs in the best possible way, the mother will be able to internalize, tolerate, and identify these unthought elements, processing them through her own alpha function and projecting them back onto the infant, in a detoxified and tolerable manner.

In this process of rêverie, the mother demonstrates to the infant a way to take a preconception (the infant's expectation of a nourishing breast, for example) and to correspond it with what Bion called "realization"-a concrete experience in the external world that provides an image to the preconception. From this crossing between preconception and realization emerges a psychological conception, the idea of a breast-as-it-meanssomething-to-me, in this example, of a good breast that the infant can dream about and even evoke in its absence. Thus, in addition to the introjection of his processed feelings, the infant introjects and identifies with a mother who is able to think. By repeating this process, the infant becomes capable of thinking about his emotional experiences, abstracting from and resorting to them even in their absence, in a growing development of a sense of self and of the world, and eventually establishes his own thinking apparatus (Bion, 1962: pp. 36-37).

\subsection{The Truth Drive}

Contrary to Freud's regressive theory, we see in both Bion and in Jung a constructive psychology in which the capacity for extraction and assimilation of real-world knowledge depends on the development of a mental apparatus that enables adapting and updating a continuous flow of raw "accretions of stimuli" to a constantly changing experiential world. Thus, this adaptation depends on the development of an ability to communicate between a universal unconsciousness and the individual's present consciousness - dependent not only on the individual's history but also on (the history of) the individual's own body —in a constant effort of integration, autonomy, and searching for individual meaning.

Unlike a mere archaeological search for infantile conflicts, these psychiatrists based their theories around a truth drive as an essential motivation in human existence. In his work, Bion repeatedly states that "healthy mental growth seems to depend on truth as the living organism depends on food. If it is lacking or deficient, the personality deteriorates" (Bion, 1965: p. 38). Using the metaphor of infection instead of hunger, Jung takes a similar position:

"Suppose a very disagreeable thing has happened to me and I don't admit it, perhaps an awful lie... The lie is there objectively, either in the conscious or in the unconscious. If I don't admit it, if I have not assimilated it, it becomes a strange body and will form an abscess in the unconscious, and the same process of suppuration begins, psychologically, as goes on in the physical body.” (Jung, 1928b: p. 20)

Jung's thought in relation to the truth drive is described in his work on individuation. Assuming for each présentification a complementary opposite element that remains unconscious but that does not cease to exert influence - constantly seeking to become conscious—Jung argues that the objective of deep psychological analysis should be to pass through recognition of these unconscious aspects and their subsequent integration into existing conscious elements in a coherent whole with meaning in a permanent approximation to the individual truth of the analysand.

Similarly, for Bion, the search for individual existential meaning passes through the processing of "things-initself" through a connection with experiential involvement in a constant oscillation between a schizo-paranoid intrinsic attitude of splitting the $\mathrm{O}$ and subsequent integration of the separated elements in a depressive position. Only by strengthening this process is it possible to develop the mind's creative and integrative abilities and, eventually, the ability to think reality. If absolute knowledge of the truth is inaccessible to man, he can nevertheless experience the truth, i.e., become the $\mathrm{O}$ of the moment. This involves the dissolution of the lies and attitudes of maladaptive and maladjusted bad faith ${ }^{28}$, developed along his individual path, in addition to knowledge of the genuine individual meaning of his mundane experiences and, eventually, of his existence.

\subsection{Intuition and Time}

Through the development of the simple evacuatory concept of the Kleinian projective identification to a means of early communication between mother and infant, Bion established the existence of a third dimension through

\footnotetext{
${ }^{28}$ This concept of bad faith was specially developed by Sartre (1957) in his proposal for an existential psychoanalysis.
} 
which this unconscious dialogue is processed. Applying this process of normal psychological development to the psychopathological states and the analytical therapeutic relationship, Bion defined projective identification as the communication method par excellence between analyst and analysand. Through this space, conceived by Jung in 1946 as a "third", an "us", a "field" that is neither patient nor analyst but a "combination" of both (Jung, 1946: para. 358), analyst and analysand are united by mutual unconsciousness ${ }^{29}$. In this union, the analyst establishes direct contact with the unconsciously manifested parts of the analysand's $\mathrm{O}$, recognizing them, processing them, and returning them in a detoxified manner to the analysand in the form of a conscious interpretation. Here, the existence in the analyst of a competent alpha function and a strong ego that can maintain its autonomy from the unconscious phenomena constantly projected by the analysand is fundamental.

This process of "at-one-ment" of the analyst with the evolutionary course of the truth of the analysand is, however, refractory to any type of intellectual articulation because at the moment when this intellectualisation is sought, the truth experienced will have already become obsolete. Like Bergson, for Bion, psychic reality is constant change, understandable only through intuitive knowledge, conceived here as direct knowledge, independent of the impeding influence of the senses. Thus, to allow the analyst to apprehend the $\mathrm{O}$ of his analysand, he must have a pause in the present from rational time and enter into a diverse irrational temporality "without memory and desire", detached from the conscious phenomena of a reflective ego (Bion, 1967; Bion, 1970: p. 41). Like the maternal rêverie, the therapeutic process must occur by resorting to a "spontaneous memory" from the psychic reality in which the analyst "must employ methods which have the counterpart of durability or extension in a domain where there is no time or space as those terms are used in the world of sense" (Bion, 1970: p. 2). Similar to Bergsonian intuition, defined as an "intelligent instinct", when reaching the truth of the moment, the analyst passes to the extension of this spontaneous memory in a space where the intuited and dispersed elements are integrated into the consciousness of the analysand in accordance with their individual meanings.

We can also find, in the constructive method of Jung, references to this process of intuition, defined as "the function that mediates perceptions in an unconscious way [independently of concrete reality]... the peculiarity of intuition is that it is neither sense perception, nor feeling, nor intellectual inference, although it can also appear in these forms. In intuition a content presents itself whole and complete, without our being able to explain or discover how this content came into existence. Intuition is a kind of instinctive apprehension no matter of what contents. Like sensation... it is an irrational... function of perception. Intuitive knowledge possesses an intrinsic certainty and conviction... The certainty of intuition rests equally on a definite state of psychic 'alertness' of whose origin is unconscious" (Jung, 1921: para. 770).

In this intuitive apprehension of units with individual meanings, Jung assumes, like Bion, the inevitability of a transposition of the boundary between a conscious and an unconscious temporality. Returning to the Bergsonian criticism of time ${ }^{30}$, Jung, in his mature theory, divides this element into fixed time (belonging to the conscious phenomena) and relative time (belonging to unconscious processes) ${ }^{31}$ Similarly, Jung defined fixed time as a quantitative artefact that is immanent from an unconscious reality: “... consciousness needs to 'de-relativize' time in order to conceptualize it; fixed time does not exist in itself but is only 'postulated' by the conscious mind" (Jung, 1952: para. 840). Relative time, in contrast, is defined as the "temporal field" through which the archetypal representations manifest themselves. In this environment, events with the same meaning characteristically present a simultaneous non-causal manifestation, defining themselves, in Jungian terminology, as synchronous elements (Jung, 1952: para. 849).

By 1907, conceiving the unconscious as a psychoid element (i.e., as an undefined element that does not yet

\footnotetext{
${ }^{29}$ In the words of Jung (1946: para. 364): “The patient, by bringing an activated unconscious content to bear upon the doctor, constellates the corresponding unconscious material in him, owing to the inductive effect which always emanates from projections in greater or lesser degree Doctor and patient thus find themselves in a relationship founded on mutual unconsciousness."

30“"One can scarcely imagine a greater contrast than that between the mathematical and the psychological mentality. The one is extremely quantitative and the other just as extremely qualitative” (Jung, 1974: p. 109).

${ }^{31}$ Despite the epistemological incompatibility with Einstein, Jung’s choice of a terminology similar to that used by the former in his formulations is noted. This was probably due to the huge popularity enjoyed by Einstein and his Theory of Relativity and Jung's effort to conceptualize his theory along the scientific lines of the time.

In the Theory of Relativity, Einstein permanently erases Newtonian concepts of absolute time and space that were hitherto still locked in the closet of Physics. However, how could Einstein "know" that "absolute" time and space did not exist? Today it is recognized that the epistemological and ontological assumptions of this theory are unjustified and even illogical, assuming that, similar to what occurred with Freud and psychoanalysis, the development of Physics throughout the twentieth century had also been cluttered by positivist epistemology, in the form of Einstein, and by its demands for a verificationist analysis, particularly in relation to the concepts of time and space (Craig \& Smith, 2007: p. 3).
} 
display a physiological or psychological nature $)^{32}$, Jung had certainly considered a synchronicity between body and mind, thus accepting the co-occurrence of archetypal physiological representations in parallel with mental ones. However, it was only 40 years later, in collaboration with the acclaimed physicist Wolfgang Pauli, that Jung brought together the elements necessary for the recovery of that concept in an inevitable extension of the synchronous phenomena to the out-of-body domain: "the position of the archetype would be located beyond the psychic sphere, analogous to the position of psychological instinct, which is immediately rooted in the stuff of the organism and, with its psychoid nature forms the bridge to matter in general” (Jung, 1947: para. 420) ) $^{33}$

With his concept of synchronicity, Jung effectively broke, like no other, the dichotomy between mind and matter, updating the philosophical concept of sympathéia in the empirical field of Depth Psychology and thus establishing a communion between not only minds but also the mind and the entire material world. In his words, mind and matter are related by "the simultaneous occurrence of a certain psychic state with one or more external events which appear as meaningful parallels to the momentary subjective state—and in certain cases, vice versa" (Jung, 1952: para. 850). Recognizing in his clinical practice the potential power of the awareness of these "meaningful coincidences" ${ }^{34}$ for psychological transformation, Jung even declared them the ultimate empirical evidence of a psychoid unconscious, responsible for the underlying ordering of an unus mundus, in accordance with a specific transcendental teleological meaning that is a priori to human consciousness (Jung, 1952: para. 942).

Therefore, as in Bergson, we see in both Jung and Bion the assumption of a transcendental temporality consubstantial to a development of synchronous phenomena, whose attribution of meaning is found in the dependence on a conscious observer. This temporality is the basis of not only an instantaneous primordial communication between the individual (un)consciousnesses but also a gemellary immanence between body-consciousness and, eventually, between this system and the material world in general. Because these phenomena occur primarily in a dimension foreign to consciousness, the temporality involved is inevitably that referred to throughout this article as relative, irrational, real, or quantum.

\section{Discussion}

"The world becomes the phenomenal world, for without conscious reflection it would not be... Here the miracle of consciousness intervenes - the second cosmogony.”

\section{G. Jung}

Separated by a generation, both Jung and Bion broke with the positivist psychoanalytic establishment in defending the need for an "ultimate reality", metaphysical in nature, as the basis of all our conscious and unconscious phenomena. Accordingly, human existence emanates from a creative dialectic between the elements of that reality and our physical material contingency, continuously representing itself in an unconscious memory with a personal teleological orientation. Posthumously emerging from this unconscious dimension (imbued in its own temporality) in a spatialized temporal dimension are all the elements necessary for the rational processing and organisation of the set of representations made conscious in our interaction with the world-in which our body, with all its physiological processes, and our own consciousness are inevitably inserted. In turn, this conscious narrative will be responsible for guiding the individual in his phenomenal existence, encouraging manipulation of the surrounding environment and the subjective selection of a specific material reality to present to the transcendental unconscious potentialities, successively affecting, in this process, its concretization.

Thus, for these analysts, human existence is identified with an unconscious in constant development, the

\footnotetext{
${ }^{32}$ In a letter dated 7 April 1907, soon after his first meeting with Jung, Freud responds to an apparent suggestion by the former in relation to the conceptualization of the unconscious as a psychoid element: "I appreciate your motives in trying to sweeten the sour apple, but I do not think you will be successful. Even if we call the unconscious 'psychoid' it will still be the unconscious, and even if we do not call the driving force in the broadened conception of sexuality 'libido', it will still be libido, and in every inference we draw from it we shall come back to the very thing from which we are trying to divert attention with our nomenclature” (McGuire, 1974: p. 18).

The term psychoid was used for the first time by Hans Driesch (1867-1941) as an element that belongs neither to the body nor the mind but that occupies an intermediate position, thus relating both. This psychoid directs the brain in its response to volitive acts of the ego to achieve individualized behaviour coherent with its history—a process described by Driesche as "I live my life” (Driesch, 1929: p. 306).

${ }^{33}$ Bion (1961: pp. 101-104), in his Experiences in Groups, also claims the existence of a "proto-mental system... in which physical and psychological or mental are undifferentiated". Later conceptualizing this "earliest matrix" as a representation of the set of beta elements, Bion describes these elements as something that "partakes of the quality of inanimate object and psychic object without any form of distinction between the two. Thoughts are things, things are thoughts; and they have personality” (Bion, 1963: p. 22).

${ }^{34}$ See the considerations of Jung after the description of the famous story of the golden scarab (Jung, 1952: paras. 843ff).
} 
product of an uninterrupted communication between physical and metaphysical elements, but which, at the present moment, is inevitably shown to be alienated from any rational conscious analysis. This analysis is doomed to always treating an outdated object because at the moment in which it is perceived, its reality will inevitably have already evolved in the uninterrupted flow of our unconscious existence.

A direct experimental demonstration of this phenomenon was conducted 30 years ago by Benjamin Libet through EEG records (Libet, 1993). In these experiments, Libet showed that the conscious will to perform a certain action arises only half a second after its initiation by the brain. As in the double-slit experiment, with the reconstruction of the history of the photon, we also see here that the perception of the action is projected retrogressively in time, making us believe that our will preceded it and that we are in control of our actions.

If this is so, why do we not present ourselves as automatons, obeying unconditionally the orders received at an unconscious level? In the same experiments, Libet reveals that despite lacking the power to initiate a specific action, it is for the volitive consciousness to decide, within 0.2 seconds between the moment it becomes aware and its actual execution, whether the action should be executed ${ }^{35}$.

This free will is thus responsible for the choice of a conscious personal narrative that seeks to be, as we have seen, as close as possible to the real truth of the individual or, in the therapeutic context, of the analysand.

When this process progresses badly and the individual moves too far away from his truth, entangling himself in a web of "lies of the flesh", consciously undertaken at one particular biographical moment, it is the analyst's responsibility to refocus the individual in his existence, approaching his conscious narrative to its unconscious equivalent. For this purpose, the analyst resorts to the only way of directly grasping the reality that is available to him—his intuition—inevitably releasing himself in this process, from the habitual sensory and rational strategies usually employed in our daily lives, in a break from conscious (pseudo)reality.

As in the maternal rêverie, after intuiting the raw emotions of his analysand, it is the analyst's responsibility to "lend" his ability to think these unconscious elements, tolerating them, identifying them, and translating them into a dialect appropriate for conscious understanding and integration by the analysand, thus strengthening, in this process, the analysand's creativity and future ability to tolerate and think his emotional states.

As we have seen, this primordial unconscious communication between analyst and analysand currently has an equivalent in the most recent developments in Quantum Physics, specifically, through quantum cryptography (Bennett, 2006) — which is a direct application of the principle of uncertainty-and both quantum teleportation and quantum computing (Bennett, 2011) — which are direct applications of the entanglement phenomenon. Underlying these developments is the idea, adopted by a large number of physicists, that quantum systems are sources of information consisting of overlapping and undefined basic dualities of the yes-no type and "awaiting" a materialized container to which they can be communicated. Thus, in this process, they concretize into only one of the informational elements: "yes" or "no". Accordingly, information is currently considered not only an infinite virtual element, responsible for structuring and organizing matter and energy ${ }^{36}$, but also the basic primordial entity that is fundamental to all physical phenomena ${ }^{37}$.

However, it has not only been in the inorganic world that these phenomena of instant communication independent of physical forces — or entanglement—have been demonstrated. In the animal world, this inter-individual

\footnotetext{
${ }^{35}$ In this veto function, we also found similarities with Cartesian philosophy, namely, its fourth meditation, which relates to truth and falsity. For Descartes, man conceives God because he discovers in him the mark of his infinity; however, he does not understand it. Thus, man receives from God autonomy to accept or reject God's commands: God proposes, and Man, through his free will, avails. Therefore, God is not to blame for man's mistakes or his sins. It is man who is mistaken, man who sins. It is man's free will that makes him deserving or guilty (Huisman \& Vergez, 1976).

${ }^{36}$ Currently, Physics conceptualizes information as an implicit component in virtually all the equations of its laws. Various recognized researchers mathematically state the relationship among matter, energy, and information. Einstein presented the relationship between matter and energy in his formula $E=\mathrm{mc}^{2}$. The connection between energy and information was described by Leo Szilard (1898-1964), while the connection between matter and information was described by Hans-Joachim Bremermann (1926-1996). In his studies, Bremermann would also define a limit on the number of symbols capable of being processed by matter, per unit of time, which became known as "Bremermann's limit” (Umpleby, 2007).

${ }^{37}$ Developing the classical concepts from Shannon’s Theory of Information, Wheeler (1990), in his thesis “It from Bit”, starts a quantum interpretation based on the concept of information, in which information constitutes the primordial universal unit: "Every it, every particle, every field of force, even the spacetime continuum itself, derives its way of action and its very existence entirely, even if in some contexts indirectly, from the detector-elicited answers to yes or no questions, binary choices, bits. Otherwise stated, all things physical, all its... must in the end submit to an information theoretic description".

If we consider the etymology of the words "information" (from the Latin informare = "that which determines form [to the mind]") and "archetype" (from the Latin archetypum = "first molded"), we cannot help but notice their functional correspondence. Thus, the celebrated physicist David Bohm uses the term "in-formation" to refer precisely to this primordial communication between the quantum and phenomenal worlds (Laszlo, 1995).
} 
communication has also been subject to countless experimental demonstrations in recent decades.

Studying the inheritance of acquired characteristics in fruit flies and the acquisition of new habits by certain species of birds, Sheldrake accepts the inevitability of an inter-individual communication of information among these beings, which goes beyond the classical physical concepts (Sheldrake, 1988). Assuming that all natural systems are associated with an information field, which at all times interacts with matter, Sheldrake extends his studies to humans, eventually positing that our brain is more like a tuning system rather than a memory storage device (Sheldrake, 1997).

In a review of mental entanglement experiments with human beings, Laszlo (1995) pinpoints their beginning to the work of J.B. Rhine with card-and-dice guessing at Duke University in the 1930s (Rhine, 1936). Since then, these experiments have become more sophisticated and reliable, with greater control of any external contaminating factors, and they have been replicated in several laboratories around the world. One of these studies was conducted at the National University of Mexico by Grinberg-Zylberbaum, Delaflor, \& Arellano (1992). Through more than 50 experiments conducted over 5 years, these researchers demonstrated how pairs of individuals placed in "Faraday cages" and, therefore, isolated acoustically and electromagnetically were able to communicate among themselves specific electroencephalographic potentials after randomized stimulation of one of them. Montecucco (2000) described other interesting experiments that demonstrate a harmonization of brain waves from groups of up to 12 individuals in meditation, while Krippner (1975) demonstrated that this interpersonal transmission of information even occurs during sleep (see review in Sherwood \& Roe, 2003).

Secondarily, these studies underline the fact that this unconscious communication is more effective the stronger the prior relationship between the subjects is. Even the EEG activities of both the analyst and analysand were compared during a therapy session, and a trend towards the superposition of their respective tracings, directly proportional to the degree of empathy (sympathy?) between them, was recorded (Grinberg-Zylberbaum, 1982).

In these studies, largely conducted using EEG records, we find not only an instantaneous transmission of information between minds but also between mind and body. The fact that these phenomena have been recorded even in states of attenuated consciousness (e.g., sleep) rules out a causality between conscious volitive and corporal phenomena, thus supporting the assumption of Jung (and Bion) relating to a simultaneous archetypal manifestation at both the mental and physiological levels, in an inevitable dissolution of the classic duality between body and mind.

A recent meta-analysis (Kemp et al., 2010) assessed the impact of depression and treatment with antidepressant drugs on heart rate variability (HRV) in patients without cardiovascular pathology. It was observed that depression is responsible for a reduction in HRV (thus increasing cardiovascular morbidity ${ }^{38}$ ) and that this physiopathological manifestation is immune to the effect of the drugs, even when there is a symptomatic relief of the depressive complaints. The authors concluded that clinical improvement after antidepressant treatment is not synonymous with normalization of cardiophysiological function; thus, the increased risk of cardiovascular morbidity is maintained.

The above study evidently suggests how a particular unconscious element that is responsible for depression and reduced HRV manifests itself in both the body and mind and how consciousness remains in a distinct plane from these manifestations. Accordingly, we have a pharmacological therapeutic action recognized at the level of the conscious symptomatic representations of depression (through the known effect of these drugs at the brain neurotransmitter level); however, the unconscious direct manifestations at the level of cardiac physiology and the mind (recognized in analytical practice, namely, through the content of dreams) remain, which suggests the persistence of the etiological factor and an eventual relapse of depression symptoms after discontinuation of these drugs.

Also of note is the work of Elio Conte and his team, who, recognizing a specific co-occurrence between psycho and pathophysiological elements, have been doing pioneering work in recent years—on the one hand, dem-

\footnotetext{
${ }^{38}$ Heart Rate Variability (HRV) is a neurophysiological marker that allows us to evaluate the action of the autonomic nervous system—related to the unconscious homeostatic regulation of the body—at the cardiovascular level, that is, through the balance between sympathetic (excitatory) and parasympathetic (inhibitory) activity. In recent decades, numerous studies have demonstrated the association of lower HRV with greater morbidity in various types of heart conditions, such as congestive heart failure and acute myocardial infarction. More recently, analysis of HRV has also revealed interest at the psychophysiological level, associating, as a rule, better physical and mental health with higher values of this marker (up to a certain limit). Specifically, at the psychiatric disorder level, a reduction in this marker, and consequent increase in cardiac morbidity, in patients with anxiety disorders, depression, bipolar affective disorder, and schizophrenia, has already been demonstrated (Shah et al., 2013; Henry, Minassian, Paulus, Geyer \& Perry, 2010; Yeragani et al., 1991).
} 
onstrating the quantum functioning of mental processes (Conte et al., 2008; Conte, 2012; Conte, 2013) and on the other hand, characterizing the communication established between the mind and various physiological systems (e.g., cardiovascular and respiratory) in a duly chaotic synchronous dynamic (Conte \& Federici, 2002; Conte, Federici, \& Zbilut, 2009; Vena et al., 2004).

By definition, no scientific experiment can ever demonstrate tout court the existence of a metaphysical reality. Nevertheless, as a whole, these works (among many others) provide reliable evidence of the existence of a reality prior to our spatialized consciousness, in which the unconscious elements are connected in a non-causal way, independent of any physical restrictions, and "waiting" to be instantly materialized at both the mental and the material levels. Inevitably, in following the theoretical premises presented in this article, these works also denounce the shortcomings of the current materialistic models of consciousness, thereby reinforcing the current need for an epistemological reformulation ${ }^{39}$.

Before moving on to the final remarks, I would like to stress that, despite the focus on the affirmation and defence of a metaphysical reality, all the authors presented in this work express in their theories the need for the existence of a reflective conscious ego, integrated into a material world, as intervening in the existential dialectic relationship between physical and metaphysical realities.

\section{Conclusion}

"Will Psycho-analysis study the living mind? Or is the authority of Freud to be used as a deterrent, a barrier to studying people?"40

\section{W. Bion}

Since the conception of the scientific method and particularly in the last two centuries, modern society has witnessed exponential growth in logical-empirical knowledge of the world, which, in turn, has given it a greater capacity to intervene and rule over nature, as well as greater material comfort in its existence. However, the price to pay for this increase in knowledge is an increase in the specialization and compartmentalization of science, which, paradoxically, ends up preventing or even reversing its progress because the experts in a given area often base their work on already-obsolete premises or their work may even be invalidated by other scientific disciplines. This has been the case in positivist epistemology, which, although officially extinct in the 1960s, still has a strong influence on the scientific community today.

I sought to show in this article how this "epistemological obstacle" (Bachelard, 2002) has been responsible, over the past century, for procrastination in exploring the findings of Quantum Physics in the affirmation of the subjective and unreal character of the scientific object and in the transmission of this knowledge to other scientific disciplines, especially to Psychology.

Using an interdisciplinary metaphor, I criticized how—-thanks to advances in Quantum Physics—many of the concepts traditionally regarded as anthropomorphic, metaphysical, or vitalist are now subject to exact scientific formulations. Given these considerations, it is critical to reappraise and validate the theories of the authors presented — which were previously regarded as unscientific — along the lines of a new science that accepts the subjective nature of their observations and the need for consideration of a transcendent metaphysical reality at the foundation of these observations.

In this holistic science, the scientist now has a new tool—intuition—which, rather than a mere phenomenal circumventing treatment, enables a "transcendent function" through which he truly enters into his object, identifying with it and thus connecting, in this process, physical and metaphysical realities. In a new methodology, the

\footnotetext{
${ }^{39}$ In these studies, the vast majority of the neuroscientists place the foundation of all conscious processes in a "primitive form of selfhood" (Baars, Ramsøy, \& Laureys, 2003; Carruthers, 2007; Dalgleish, 2004; Damasio, 1999; Gallagher, 2000; Gallagher \& Frith, 2003; Gallagher \& Zahavi, 2005; Lambie \& Marcel, 2002; Legrand, 2005; Panksepp, 1998a, 1998b, 2007a, 2007b; Pinku \& Tzelgov, 2006; Zahavi, 2003), represented as a somatosensory homunculus at the brainstem level. This primordial corporal representation, in which all of the most elaborate conscious phenomena sustain themselves, inevitably results from a fundamentally spatial definition, established through tactile (internal or external) and visual coordinates, inherent, as is known, to the notions of proximity and distance, respectively.

A smaller body of research has placed emphasis on the emergence of consciousness from the complexities of synchronous neurodynamics between various intracerebral processes, such as the synchronization of gamma waves and other synchronization mechanisms in cortical regions (Edelman, 2006; Uhlhaas \& Singer, 2006).

In general, none of the neuroscientific correlations established until now have been able to demonstrate an unequivocal causal relationship between the mechanisms of brain activity and the human "consciousness", and thus, the "hard problem" of consciousness has yet to be resolved (Chalmers, 1995).

${ }^{40}$ Question asked by Bion (1979) in the last paragraph of his last article: Making the Best of a Bad Job.
} 
intuited knowledge is then necessarily and duly extended in a public language, subject to logical scrutiny and, finally, integrated into a valid empirical-theoretical body, thus ensuring its scientific rigour and replicability ${ }^{41}$.

Due to its privileged position in the study of this quantum unconscious - the ultimate reality-Psychoanalysis has a decisive role in this epistemological restructuring. Currently conceived as an instrument for the approximation of consciousness to truth, this scientific discipline has a responsibility to show to a tendentiously schizoid society, increasingly affected by narcissistic conditions, evidence of a transcendental dimension that binds us all into a collective project, in an ultimate effort to integrate these split realities of postmodern mentality. Reaching this depressive position, a more realistic and integrated knowledge of the world will inevitably be attained, which, in turn, will be responsible for the deconstruction of a psychotic anthropocentric conception of the Cosmos, in which Man, through a self-proclaimed omniscience, seeks to explain everything through his reasoning.

Nevertheless, to complete this project, Psychoanalysis must first undergo the self-therapeutic process of overcoming its Freudian legacy of submission to a positivistic science; only then will it be able to assert itself as the paradigmatic discipline of a new super-science.

\section{Acknowledgements}

I thank the entire team of the Tavistock and Portman Clinic in London for the support and the thought-provoking discussions that made this work possible. Special thanks go to Dr. David Bell, Dr. Julien Stern, Prof. Peter Hobson, Francesca Hume, Joanne Stubley, Joanna Rosenthall, Edna O’Shaughnessye, and, outside of Tavi, Ann Cannon, Neville Symington and Prof. Elio Conte.

\section{References}

Antoniaou, I., \& Christidis, T. (2010). Bergson’s Time and the Time Operator. Mind and Matter, 8, 185-202.

Aspect, A., Grangier, P., \& Roger, G. (1981). Experimental Tests of Realistic Local Theories via Bell’s Theorem. Physical Review Letters, 47, 460-463. http://dx.doi.org/10.1103/PhysRevLett.47.460

Assoun, P. L. (1981). Introduction à L'épistémologie Freudienne. Paris: Payot.

Athanassakis, A. N. (2004). Hesiod: Theogony, Works and Days, Shield. Baltimore, MD: Johns Hopkins University Press.

Baars, B. J., Ramsoy, T. Z., \& Laureys, S. (2003). Brain, Conscious Experience and the Observing Self. Trends in Neuroscience, 26, 671-675. http://dx.doi.org/10.1016/j.tins.2003.09.015

Bachelard, G. (2002). The Formation of the Scientific Mind. Manchester: Clinamen.

Barnes, J. (1995). The Cambridge Companion to Aristotle. Cambridge: Cambridge University Press.

Bell, J. S. (1964). On the Einstein Podolsky Rosen Paradox. Physics, 1, 195-200.

Bennett, C. H. (2006). Quantum Cryptography: Principles and Prospects (Quantumkryptographie: Prinzipien und Ausblick). IT-Information Technology, 48, 332-335. http://dx.doi.org/10.1524/itit.2006.48.6.332

Bennett, C. H. (2011). Theory of Entanglement and Entanglement-Assisted Communication. Paper presented at the APS March Meeting Abstracts.

Bergson, H. (1888). Time and Free Will: An Essay on the Immediate Data of Consciousness. http://intersci.ss.uci.edu/26A0BE46-AECA-497C-8140-4C43C9EA56B8/FinalDownload/DownloadId-11000C14D82C15 4EC1165CD746C48088/26A0BE46-AECA-497C-8140-4C43C9EA56B8/wiki/eBooks/BOOKS/Bergson/Time\%20and\% 20Free\%20Will\%20Bergson.pdf

Bergson, H. (1903). An Introduction to Metaphysics. http://www.reasoned.org/dir/lit/int-meta.pdf

Bergson, H. (1911). Creative Evolution. New York: Henry Holt and Company.

Bergson, H. (1965). Duration and Simultaneity: With Reference to Einstein's Theory. Indianapolis, IN: Bobbs-Merrill.

Bergson, H., Paul, N. M., \& Palmer, W. S. (1896). Matter and Memory. London: George Allen and Unwin Memory, 1911.

Billinsky, J. M. (1969). Jung and Freud (the End of a Romance). Andover Newton Quarterly, 10, 39-43.

\footnotetext{
${ }^{41}$ This way of practising science, using intuition, is not completely unprecedented in history. There are reports from various scientists-including Einstein and Bohr-related to obtaining this type of intuitive knowledge and the importance of this in the development of their formulations. One of the best known cases involved the German chemist Friedrich Kekule (1829-1896), who, prior to the discovery of the circular molecular structure of benzene, described the following dream: "Again the atoms were juggling before my eyes... my mind's eye, sharpened by repeated sights of a similar kind, could now distinguish larger structures of different forms and in long chains, many of them close together; everything was moving in a snake-like and twisting manner. Suddenly... one of the snakes got hold of its own tail and the whole structure was mockingly twisting in front of my eyes. As if struck by lightning, I awoke...” He concludes his report by proposing: "Let us learn to dream, gentlemen, and then we may perhaps find the truth.” (Strunz, 1993).
} 
Bion, W. R. (1961). Experiences in Groups and Other Papers. London: Karnac Books. http://dx.doi.org/10.4324/9780203359075

Bion, W. R. (1962). Learning from Experience. London: Karnac Books.

Bion, W. R. (1963). Elements of Psycho-Analysis. London: William Heinemann Medical Books Ltd. (Reprinted London: Karnac Books)

Bion, W. R. (1965). Transformations. London: William Heinemann Medical Books Ltd. (Reprinted London: Karnac Books, 2002)

Bion, W. R. (1967). Notes on Memory and Desire. In R. Lang (Ed.), Classics in Psychoanalytic Technique. New York and London: Jason Aronson, Inc.

Bion, W. R. (1970). Attention and Interpretation. London: Tavistock Publications.

Bion, W. R. (1979). Making the Best of a Bad Job. In Clinical Seminars and Other Works. London: Karnac Books, 2000. (Reprinted London: Karnac Books, 1994)

Blass, R. B. (2011). Introduction to “On the Value of 'late Bion' to Analytic Theory and Practice”. The International Journal of Psychoanalysis, 92, 1081-1088. http://dx.doi.org/10.1111/j.1745-8315.2011.00503.x

Bohr, N. (1935a). Quantum Mechanics and Physical Reality. Nature, 136, 65. http://dx.doi.org/10.1038/136065a0

Bohr, N. (1935b). Can Quantum-Mechanical Description of Physical Reality Be Considered Complete? Physical Review, 48, 696-702. http://dx.doi.org/10.1103/PhysRev.48.696

Bohr, N. (1959). Discussion with Einstein on Epistemological Problems in Atomic Physics. In P. A. Schilpp (Ed.), Albert Einstein: Philosopher-Scientist. New York: Harper and Row.

Caldwell, R. S. (1993). The Origin of the Gods: A Psychoanalytic Study of Greek Theogonic Myth. Oxford: Oxford University Press.

Capek, M. (1969). Bergson's Theory of Matter and Modern Physics. In P. Gunter (Ed.), Bergson and the Evolution of Physics. Knoxville, TN: University of Tennessee Press.

Capek, M. (1971). Bergson and Modern Physics: A Reinterpretation and Re-Evaluation. Dordrecht: Reidel.

Capek, M. (2012). Bergson and Modern Physics: A Reinterpretation and Re-Evaluation (Vol. 7). Springer Science \& Business Media.

Carruthers, G. (2007). A Model of the Synchronic Self. Consciousness and Cognition, 16, 533-550. http://dx.doi.org/10.1016/j.concog.2006.06.002

Chalmers, D. J. (1995). Facing Up to the Problem of Consciousness. Journal of Consciousness Studies, 2, $200-219$.

Comte, A., \& Lenzer, G. (1998). Auguste Comte and Positivism: The Essential Writings. New Brunswick, NJ: Transaction Publishers.

Conte, E. (2012). What Is the Reason to Use Clifford Algebra in Quantum Cognition? Part I: “It from Qubit” on the Possibility That the Amino Acids Can Discern between Two Quantum Spin States. NeuroQuantology, 10, 561-565. http://dx.doi.org/10.14704/nq.2012.10.3.540

Conte, E. (2013). What Is the Reason to Use Clifford Algebra in Quantum Cognition? Part II: Information, Cognition and the Principle of Existence Are Intrinsically Structured in the Quantum Model of Reality. NeuroQuantology, 11, 34-46. http://dx.doi.org/10.14704/nq.2013.11.1.644

Conte, E., \& Federici, A. (2002). Chaotic Parameters in Time Series of ECG, Respiratory Movements and Arterial Pressure. In G. Nardulli, \& S. Stramaglia (Eds.), Modelling Biomedical Signals: Bari, Italia, 19-21, September 2001. River Edge, NJ: World Scientific Publishing Co. Pte. Ltd.

Conte, E., Federici, A., \& Zbilut, J. P. (2009). A New Method Based on Fractal Variance Function for Analysis and Quantification of Sympathetic and Vagal Activity in Variability of R-R Time Series in ECG Signals. Chaos, Solitons \& Fractals, 41, 1416-1426. http://dx.doi.org/10.1016/j.chaos.2008.05.025

Conte, E., Khrennikov, A., Todarello, O., Federici, A., \& Zbilut, J. P. (2008). A Preliminary Experimental Verification on the Possibility of Bell Inequality Violation in Mental States. NeuroQuantology, 6, 214-221. http://dx.doi.org/10.14704/nq.2008.6.3.178

Craig, W. L., \& Smith, Q. (2007). Einstein, Relativity and Absolute Simultaneity. New York: Routledge.

Dalgleish, T. (2004). Timeline: The Emotional Brain. Nature Reviews Neuroscience, 5, 583-589. http://dx.doi.org/10.1038/nrn1432

Damasio, A. R. (1999). The Feeling of What Happens: Body and Emotion in the Making of Consciousness. New York: Harcourt Incorporated.

De Broglie, L. (1947). The Concept of Contemporary Physics and Bergson's Ideas on Time and Motion. In P. A. Y. Gunter (Ed.), Bergson and the Evolution of Physics (pp. 45-62). Knoxville, TN: University of Tennessee Press. 
De Broglie, L. (1970). The Reinterpretation of Wave Mechanics. Foundations of Physics, 1, 5-15. http://dx.doi.org/10.1007/BF00708650

Deleuze, G. (1988). Bergsonism. New York: Zone Books.

Descartes, R. (2010). Meditations. London: Penguin.

Dicker, G. (2013). Descartes: An Analytical and Historical Introduction. New York: Oxford University Press. http://dx.doi.org/10.1093/acprof:osobl/9780195380323.001.0001

Dobbs, B. J. T. (1991). The Janus Face of Genius. Cambridge: The University Press.

Driesch, H. (1929). The Science \& Philosophy of the Organism. London: A. \& C. Black.

Edelman, G. M. (2006). Second Nature: Brain Science and Human Knowledge. London: Yale University Press.

Einstein, A., Born, M., \& Born, H. (1971). The Born-Einstein Letters: Correspondence between Albert Einstein and Max and Hedwig Born from 1916-1955, with Commentaries by Max Born. New York: Macmillan.

Einstein, A., Podolsky, B., \& Rosen, N. (1935). Can Quantum-Mechanical Description of Physical Reality Be Considered Complete? Physical Review, 47, 777-780. http://dx.doi.org/10.1103/PhysRev.47.777

Ellenberg, H. F. (1970). Pierre Janet and Psychological Analysis. In H. F. Ellenberger (Ed.), Discovery of the Unconscious: The History and Evolution of Dynamic Psychiatry (pp. 331-417). New York: Basic Books.

Evans, R. I. (1979). Jung on Elementary Psychology: A Discussion between CG Jung and R. I. Evans. London: Routledge \& Kegan Paul.

Feynman, R. P., Leighton, R. B., \& Sands, M. L. (1965). The Feynman Lectures on Physics: Quantum Mechanics (Vol. 3). Reading, MA: Addison-Wesley.

Freedman, S. J., \& Clauser, J. F. (1972). Experimental Test of Local Hidden-Variable Theories. Physical Review Letters, 28, 938-941. http://dx.doi.org/10.1103/PhysRevLett.28.938

Freud, S. (1896a). Studies on Hysteria. Standard Ed. (Vol. 2). London: Hogarth Press. (Printed 1955)

Freud, S. (1896c). The Etiology of Hysteria. Standard Ed. (Vol. 3. pp. 187-221). (1962)

Freud, S. (1905). Three Essays on the Theory of Sexuality. Standard Ed. Vol. 7. (1953)

Freud, S. (1914). On narcissism: An Introduction. Standard Ed. (Vol. 14. pp. 67-102). (1957)

Freud, S. (1921). Psycho-Analysis and Telepathy. Standard Ed. (Vol. 18. pp. 173-193). (1955)

Freud, S. (1923). Two Encyclopaedia Articles. Standard Ed. (Vol. 18. pp. 233-259). (1955)

Freud, S. (1924). An Autobiographical Study. Standard Ed. (Vol. 20. pp. 1-74). (1959)

Freud, S. (1940). Some Elementary Lessons in Psychoanalysis. Standard Ed. (Vol. 23, pp. 279-286).

Gallagher, H. L., \& Frith, C. D. (2003). Functional Imaging of “Theory of Mind”. Trends in Cognitive Sciences, 7, 77-83. http://dx.doi.org/10.1016/S1364-6613(02)00025-6

Gallagher, S. (2000). Philosophical Conceptions of the Self: Implications for Cognitive Science. Trends in Cognitive Sciences, 4, 14-21. http://dx.doi.org/10.1016/S1364-6613(99)01417-5

Gallagher, S., \& Zahavi, D. (2005). Phenomenological Approaches to Self-Consciousness. In E. N. Zalta (Ed.), Stanford Encyclopedia of Philosophy. Stanford Center for the Study of Language and Information. http://plato.stanford.edu/archives/spr2005/entries/self-consciousness-phenomenological/

Grinberg-Zylberbaum, J. (1982). Psychophysiological Correlates of Communication, Gravitation and Unity. Psychoenergetics, 4, 227-256.

Grinberg-Zylberbaum, J., Delaflor, M., \& Arellano, M. S. (1992). Human Communication and the Electrophysiological Activity of the Brain. Subtle Energies \& Energy Medicine Journal Archives, 3, 25-43.

Grosskurth, P. (1991). The Secret Ring: Freud's Inner Circle and the Politics of Psychoanalysis. London: Jonathan Cape.

Grosskurth, P. (1998). Psychoanalysis: A Dysfunctional Family? Journal of Analytical Psychology, 43, 87-95. http://dx.doi.org/10.1111/1465-5922.00010

Hart, H. (1980). The Impasse of Rationality Today. Tornoto: Association for the Advancement of Christian Scholarship.

Heisenberg, W. (1999). Physics and Philosophy: The Revolution in Modern Science (Vol. 18). New York: Prometheus Books.

Heisenberg, W., \& Casimir, H. B. G. (1974). Across the Frontiers. Physics Today, 27, 48. http://dx.doi.org/10.1063/1.3128807

Henry, B. L., Minassian, A., Paulus, M. P., Geyer, M. A., \& Perry, W. (2010). Heart Rate Variability in Bipolar Mania and Schizophrenia. Journal of Psychiatric Research, 44, 168-176. http://dx.doi.org/10.1016/j.jpsychires.2009.07.011 
Huisman, D., \& Vergez, A. (1976). História dos Filósofos Ilustrada Pelos Textos. Tradução de Lélia de Almeida Gonzalez. Rio de Janeiro/São Paulo: Livraria Freitas Bastos.

Huxley, J. S. (1899-1980). Papers of Julian Sorell Huxley (MS 50). Houston, TX: Woodson Research Center, Fondren Library, Rice University.

Jaeger, G. (2009). Entanglement, Information, and the Interpretation of Quantum Mechanics. New York: Springer Verlag. http://dx.doi.org/10.1007/978-3-540-92128-8

Janet, P. (1903). Les Obséssions et la Psychasténie (Vol. 2). Paris: Alcan.

Jones, E. (1909-1910). The God-Complex. In Essays in Applied Psychoanalysis (Vol. 2). London: The Hogarth Press Ltd. and the Institute of Psycho-Analysis.

Jones, E. (1955). The Life and Work of Sigmund Freud, Vol. II: Years of Maturity. London: The Hogart Press.

Jung, C. G. (1896). The Border Zones of Exact Science. In The Zolfingia Lectures. London: Routledge.

Jung, C. G. (1897). Some Thoughts on Psychology. In The Zolfingia Lectures. London: Routledge.

Jung, C. G. (1914). The Content of the Psychoses, Part II. In C. E. Long (Ed.), Collected Papers on Analytical Psychology. London: Baillière, Tindal Ancox, 1917.

Jung, C. G. (1921). Psychological Types. In Collected Works (Vol. 6). Princeton, NJ: Princeton University Press.

Jung, C. G. (1928a). Lecture III. Child Development and Education. Collected Works, 17, 98-126.

Jung, C. G. (1928b). Lecture II. In W. McGuire (Ed.), Dream Analysis: Notes of the Seminar Given in 1928-1930. Part I. London: Routledge, 1995.

Jung, C. G. (1938). On the Psychological Aspects of the Mother Archetype. Collected Works (Vol. 9). Princeton NJ: Princeton University Press.

Jung, C. G. (1939). On the Psychogenesis of Schizophrenia. Collected Works (Vol. 3). London: Routledge \& Kegan Paul, 1960.

Jung, C. G. (1946). The Psychology of the Transference. Collected Works (Vol. 16). Princeton, NJ: Princeton University Press.

Jung, C. G. (1947). On the Nature of the Psyche. Collected Works (Vol. 8). Princeton, NJ: Princeton University Press.

Jung, C. G. (1952). Synchronicity: An Acausal Connecting Principle. Collected Works (Vol. 8). Princeton, NJ: Princeton University Press.

Jung, C. G. (1953). Psychological Commentary on the Tibetan Book of the Dead. Collected Works (Vol. 11). London: Routledge \& Kegan Paul, 1958.

Jung, C. G. (1963). Memories \& R. J. A. Dreams. London: Collins and Routledge \& Kagen Paul.

Jung, C. G. (1974). Letters, Volume 2: 1951-1961. In A. G (Ed.), Bollingen Series XCV2. Princeton, MA: Princeton University Press.

Kant, I. (2007/1781). Critique of Pure Reason (2nd ed.). Cambridge, UK: Cambridge University Press.

Kemp, A. H., Quintana, D. S., Gray, M. A., Felmingham, K. L., Brown, K., \& Gatt, J. M. (2010). Impact of Depression and Antidepressant Treatment on Heart Rate Variability: A Review and Meta-Analysis. Biological Psychiatry, 67, $1067-1074$. http://dx.doi.org/10.1016/j.biopsych.2009.12.012

Klein, M. (1996). Notes on Some Schizoid Mechanisms. In M. Masud, \& R. Khan (Eds.), The Writtings of Melanie Klein. Vol. III: Envy and Gratitude and Other Works (1946-1963). London: The Hogarth Press and the Institute of PsychoAnalysis, 1987.

Koestler, A. (1975). The Act of Creation. London: Picador, Pan Books.

Krippner, B. S. (1975). Dreams and Other Altered Conscious States. Journal of Communication, 25, 173-182. http://dx.doi.org/10.1111/j.1460-2466.1975.tb00567.x

Lambie, J. A., \& Marcel, A. J. (2002). Consciousness and the Varieties of Emotion Experience: A Theoretical Framework. Psychological Review, 109, 219-259. http://dx.doi.org/10.1037/0033-295X.109.2.219

Laszlo, E. (1995). The Interconnected Universe: Conceptual Foundations of Transdisciplinary Unified Theory. London: World Scientific Publishing Company Incorporated.

Legrand, D. (2005). Being a Body. Trends in Cognitive Sciences, 9, 413-414. http://dx.doi.org/10.1016/j.tics.2005.06.007

Libet, B. (1993). Unconscious Cerebral Initiative and the Role of Conscious Will in Voluntary Action. In B. Libet (Ed.), Neurophysiology of Consciousness (pp. 269-306). Boston, MA: Birkhäuser Boston.

Maylan, C. E. (1929). Freuds Tragischer Komplex: Eine Analyse der Psychoanalyse. München: Ernst Reinhardt Verlag.

McGuire, W. (Ed.) (1974). The Freud-Jung Letters. London: Routledge \& Kegan Paul. 
Meltzer, D. (1978). Catastrophic Change and the Mechanisms of Defense. In D. Meltzer (Ed.), The Kleinian Development. Part III. London: Karnac Books.

Montecucco, N. F. (2000). Cyber. La Vision Olistica. Una Scienza Unitaria dell’Uomo e del Mondo. Roma: Edizioni Mediterranee.

Morin, E. (1977). La Méthode. Paris: Editions du Seuil.

Neumann, J. V. (1955). Mathematical Foundations of Quantum Mechanics. Princeton, NJ: Princeton University Press.

Neurath, M., \& Cohen, R. S. (Eds.) (1973). Empiricism and Sociology (Vol. 1). Berlin: Springer Science \& Business Media.

Panksepp, J. (1998a). Affective Neuroscience: The Foundations of Human and Animal Emotions. New York: Oxford University Press.

Panksepp, J. (1998b). The Periconscious Substrates of Consciousness: Affective States and the Evolutionary Origins of the SELF. Journal of Consciousness Studies, 5, 566-582.

Panksepp, J. (2007a). The Neuroevolutionary and Neuroaffective Psychobiology of the Prosocial Brain. In R. I. M. D. Dunbar, \& L. Barrett (Eds.), Oxford Handbook of Evolutionary Psychology (pp. 145-162). Oxford: Oxford University Press.

Panksepp, J. (2007b). Affective Consciousness. In M. Velmans, \& S. Schneider (Eds.), The Blackwell Companion to Consciousness (pp. 114-129). Malden, MA: Blackwell Publishing, Ltd.

Pinku, G., \& Tzelgov, J. (2006). Consciousness of the Self (COS) and Explicit Knowledge. Consciousness and Cognition, 15, 655-661. http://dx.doi.org/10.1016/j.concog.2005.10.001

Plotinus (2004). The Six Enneads. Chicago, IL: Kessinger Publishing.

Popper, K. (1999). Karl Popper and W. V. O. Quine. In R. H. Popkin (Ed.), The Columbia History of Western Philosophy (p. 647). New York: Columbia University Press.

Putnam, J. J. (1909-1910). Personal Impressions of Sigmund Freud and His Work, with Special Reference to His Recent Lectures at Clark University. The Journal of Abnormal Psychology, 4, 293-310.

Rhine, J. B. (1936). Some Selected Experiments in Extra-Sensory Perception. The Journal of Abnormal and Social Psychology, 31, 216-228. http://dx.doi.org/10.1037/h0063236

Roazen, P., \& Marić, S. (1973). Brother Animal: The Story of Freud and Tausk. London: Penguin Books.

Rosenblum, B., \& Kuttner, F. (2011). Quantum Enigma: Physics Encounters Consciousness. Oxford: Oxford University Press.

Roustang, F. (1986). Dire Mastery: Discipleship from Freud to Lacan. Washington DC: American Psychiatric Press.

Sartre, J. P. (1957). Being and Nothingness: An Essay on Phenomenological Ontology (Translated and with an Introduction by Hazel E. Barnes). London: Methuen \& Co Ltd.

Schrödinger, E. (1995). The Interpretation of Quantum Mechanics: Dublin Seminars (1949-1955) and Other Unpublished Essays. Woodbridge, CT: OxBow Press.

Shah, A. J., Lampert, R., Goldberg, J., Veledar, E., Bremner, J. D., \& Vaccarino, V. (2013). Posttraumatic Stress Disorder and Impaired Autonomic Modulation in Male Twins. Biological Psychiatry, 73, 1103-1110. http://dx.doi.org/10.1016/j.biopsych.2013.01.019

Sheldrake, R. (1988). The Presence of the Past: Morphic Resonance and the Habits of Nature. Vermont: Park Street Press, 1995.

Sheldrake, R. (1997). Mind, Memory and Archetype. Morphic Resonance and the Collective Unconscious. Part I. Psychological Perspectives, 18, 9-25.

Sherwood, S., \& Roe, C. A. (2003). A Review of Dream ESP Studies Conducted Since the Maimonides Dream ESP Programme. Journal of Consciousness Studies, 10, 85-109.

Strunz, F. (1993). Preconscious Mental Activity and Scientific Problem-Solving: A Critique of the Kekulé Dream Controversy. Dreaming, 3, 281-294. http://dx.doi.org/10.1037/h0094386

Symington, J., \& Symington, N. (2002). The Clinical Thinking of Wilfred Bion. London, New York: Routledge.

Uhlhaas, P. J., \& Singer, W. (2006). Neural Synchrony in Brain Disorders: Relevance for Cognitive Dysfunctions and Pathophysiology. Neuron, 52, 155-168. http://dx.doi.org/10.1016/j.neuron.2006.09.020

Umpleby, S. A. (2007). Physical Relationships among Matter, Energy and Information. Systems Research and Behavioral Science, 24, 369-372. http://dx.doi.org/10.1002/sres.761

Vena, A., Conte, E., Perchiazzi, G., Federici, A., Giuliani, R., \& Zbilut, J. P. (2004). Detection of Physiological Singularities in Respiratory Dynamics Analyzed by Recurrence Quantification Analysis of Tracheal Sounds. Chaos, Solitons \& Fractals, 22, 869-881. http://dx.doi.org/10.1016/j.chaos.2004.03.005 
Vermote, R. (2011). On the Value of “Late Bion” to Analytic Theory and Practice. The International Journal of Psychoanalysis, 92, 1089-1098. http://dx.doi.org/10.1111/j.1745-8315.2011.00500.x

Webster, R. (1995). Why Freud Was Wrong: Sin, Science and Psychoanalysis. New York: Basic Books.

Wheeler, J. A. (1990). Information, Physics, Quantum: The Search for Links. In W. Zurek (Ed.), Complexity, Entropy, and the Physics of Information. Redwood City, CA: Addison-Wesley Publishing Company.

Whitaker, A. (1998). John Bell and the Most Profound Discovery of Science. Physics World, 11, 29-34. http://dx.doi.org/10.1088/2058-7058/11/12/24

Winnicott, D. W. (1963). D.W.W.'s Dream Related to Reviewing Jung. In C. C. Winnicott, R. Shepard, \& M. Davis (Eds.), Psycho-Analytic Explorations. London: Karnac Books, 1989/2010.

Winnicott, D. W. (1964). Memories, Dreams, Reflections. International Journal of Psycho-Analysis, 45, 450-455.

Wittgenstein, L. (1922). Tractatus Logico-Philosophicus (p. 2010). London: Kegan Paul, Trench, Truber \& Co., Ltd. http://www.gotenberg.org/files/5740/5740-pdf.pdf

Yeragani, V. K., Pohl, R., Balon, R., Ramesh, C., Glitz, D., Jung, I., \& Sherwood, P. (1991). Heart Rate Variability in Patients with Major Depression. Psychiatry Research, 37, 35-46. http://dx.doi.org/10.1016/0165-1781(91)90104-W

Yerushalmi, Y. H. (1993). Freud's Moses: Judaism Terminable and Interminable. New Haven, CT: Yale University Press.

Zahavi, D. (2003). Phenomenology of the Self. In T. Kircher, \& A. David (Eds.), The Self in Neuroscience and Psychiatry. Cambridge, UK: Cambridge University Press.

\section{Submit or recommend next manuscript to SCIRP and we will provide best service for you:}

Accepting pre-submission inquiries through Email, Facebook, Linkedin, Twitter, etc A wide selection of journals (inclusive of 9 subjects, more than 200 journals)

Providing a 24-hour high-quality service

User-friendly online submission system

Fair and swift peer-review system

Efficient typesetting and proofreading procedure

Display of the result of downloads and visits, as well as the number of cited articles

Maximum dissemination of your research work

Submit your manuscript at: http://papersubmission.scirp.org/ 